\title{
Joint effect of organic acids and inorganic salts on cloud droplet activation
}

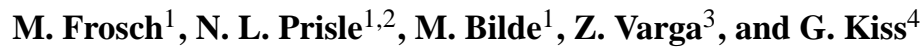 \\ ${ }^{1}$ Department of Chemistry, University of Copenhagen, Denmark \\ ${ }^{2}$ Department of Physics, Division of Atmospheric Sciences, University of Helsinki, Finland \\ ${ }^{3}$ Department of Earth and Environmental Sciences, University of Pannonia, Hungary \\ ${ }^{4}$ Air Chemistry Group of Hungarian Academy of Sciences, University of Pannonia, Hungary
}

Received: 2 July 2010 - Published in Atmos. Chem. Phys. Discuss.: 26 July 2010

Revised: 31 March 2011 - Accepted: 1 April 2011 - Published: 28 April 2011

\begin{abstract}
We have investigated CCN properties of internally mixed particles composed of one organic acid (oxalic acid dihydrate, succinic acid, adipic acid, citric acid, cis-pinonic acid, or Nordic reference fulvic acid) and one inorganic salt (sodium chloride or ammonium sulphate). Surface tension and water activity of aqueous model solutions with concentrations relevant for $\mathrm{CCN}$ activation were measured using a tensiometer and osmometry, respectively. The measurements were used to calculate Köhler curves and critical supersaturations, which were compared to measured critical supersaturations of particles with the same chemical compositions, determined with a cloud condensation nucleus counter. Surfactant surface partitioning was not accounted for. For the aqueous solutions containing cis-pinonic acid and fulvic acid, a depression of surface tension was observed, but for the remaining solutions the effect on surface tension was negligible at concentrations relevant for cloud droplet activation. The surface tension depression of aqueous solutions containing both organic acid and inorganic salt was approximately the same as or smaller than that of aqueous solutions containing the same mass of the corresponding pure organic acids. Water activity was found to be highly dependent on the type and amount of inorganic salt. Sodium chloride was able to decrease water activity more than ammonium sulphate and both inorganic salts are predicted to have a smaller Raoult term than the studied organic acids. Increasing the mass ratio of the inorganic salt led to a decrease in water activity. Water activity measurements were compared to results from the E-AIM model and values estimated from both constant and variable van't Hoff factors. The correspondence between measurements and estimates was overall good, except for highly concentrated solutions. Critical supersatura-
\end{abstract}

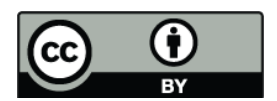

Correspondence to: $\mathrm{M}$. Frosch (mia@kiku.dk) tions calculated with Köhler theory based on measured water activity and surface tension, but not accounting for surface partitioning, compared well with measurements, except for the solutions containing sodium chloride and oxalic acid or one of the more surface active organic compounds. In such cases, significantly lower values were obtained from Köhler theory than the measured critical supersaturations with deviations above $50 \%$ for a $60 \mathrm{~nm}$ particle containing $50 \%$ (dry mass) of Nordic reference fulvic acid, suggesting that surfactant partitioning and/or an effect of sodium chloride on solubility of the organic component is important.

\section{Introduction}

Atmospheric aerosols contain numerous organic and inorganic compounds. The organic fraction has been estimated to account for $20 \%$ to $90 \%$ of the total fine aerosol mass (Kanakidou et al., 2005). It has been shown that organic as well as mixed particles can influence cloud formation by acting as cloud condensation nuclei $(\mathrm{CCN}$; e.g. Cruz and Pandis, 1997; Corrigan and Novakov, 1999; Prenni et al., 2001; Giebl et al., 2002; Kumar et al., 2003; Bilde and Svenningsson, 2004; Broekhuizen et al., 2004b; Rissman et al., 2007). The interactions between aerosols and water in the atmosphere leading to the formation of cloud droplets (the socalled indirect aerosol effect, e.g. Twomey, 1984; Albrecht, 1989) can potentially have a great effect on the global radiation balance and global climate, but is not well understood (IPCC, 2007).

In the atmosphere the formation of cloud droplets is determined by the size distribution and chemical composition of the cloud condensation nuclei as well as dynamic parameters such as updraft velocity and liquid water content (e.g. Nenes, et al., 2002; Feingold, 2003; Lance et al., 2004; Koehler et

Published by Copernicus Publications on behalf of the European Geosciences Union. 
al., 2006; Ervens et al., 2010). The relative importance of these effects is not yet fully clarified. In this work we address the effect of particle chemical composition on the critical supersaturation.

Köhler theory (Köhler, 1936) or Köhler theory modified to account for limited solubility (e.g. Bilde and Svenningsson, 2004) or surface tension lowering (e.g. Prisle et al., 2008) can be used to model cloud droplet formation and determine the critical supersaturaion of aerosol particles if parameters such as surface tension and water activity of the aqueous solution droplets are available. However, for many atmospherically relevant species and for mixtures between them these parameters are not known.

The surface tension of an aqueous solution containing only an inorganic salt (e.g. sodium chloride or ammonium sulphate) is only slightly higher than the surface tension of pure water (Low, 1969), and in activating aqueous solution droplets, surface tension can be approximated to the surface tension of pure water. This is not the case for many organic components, such as humic-like substances (HULIS) or long-chained carboxylic acids, which can depress surface tension of aqueous solutions significantly (e.g. Shulman et al., 1996; Facchini et al., 1999; Kiss et al., 2005; Prisle et al., 2008). In the past few years some studies have been made on surface tension measurements of cloud water (Hitzenberger et al., 2002; Decesari et al., 2004), fog water and aerosol extract (Seidl and Hänel, 1983; Capel et al., 1990; Facchini et al., 2000; Decesari et al., 2004; Kiss et al., 2005), and also of individual organic compounds (Shulman et al., 1996; Ervens et al., 2004; Tuckermann and Cammenga, 2004; Varga et al., 2007). However, information about water activity of aerosol samples and model systems is still sparse, making it difficult to accurately predict critical supersaturation of particles composed of organic compounds or of mixtures of organic and inorganic compounds. So far, a few studies exist on cloud droplet formation of model mixtures, e.g. Gorbunov et al. (1999), Raymond and Pandis (2003), Broekhuizen et al. (2004a), Henning et al. (2005), Svenningsson et al. (2006), Padró et al. (2007), Prisle et al. (2010), Kristensson et al. (2010). Booth et al. (2009) have addressed the surface tension of mixtures of dicarboxylic acids and salt and the implications for cloud droplet formation.

When organic compounds are mixed with inorganic salts in aqueous solutions, one of two different effects on surface tension can be expected: Either the surface tension of the solution is higher than in an aqueous solution of the pure organic component, because the salt has partially replaced the organic compound. Alternatively, the presence of inorganic salts in the solution can enhance the surface tension depression of organic surfactants by forcing the organic compound to the solution-air interface. Such a phenomenon was observed when cis-pinonic acid, fulvic acids or humic acids were dissolved in a $2 \mathrm{M}$ ammonium sulphate aqueous solution (Shulman et al., 1996; Kiss et al., 2005).
In this study we focus on six organic and two inorganic compounds, which are considered atmospherically relevant (e.g. Saxena and Hildemann, 1996; Allen et al., 2000; Cheng et al., 2004): Ammonium sulphate (AS), sodium chloride (SC), oxalic acid dihydrate (OA), succinic acid (SA), adipic acid (AA), citric acid (CA) and cis-pinonic acid (cPA). In addition, we have studied the model substance Nordic reference fulvic acid (NRFA) as a representative of HULIS. Water activity and surface tension have been determined experimentally for a series of aqueous solutions of mixtures of organic acids and inorganic salts and parameterized as a function of solute concentration. The parameterizations are used in Köhler theory to calculate critical supersaturation as a function of the dry particle diameter, and the predictions are compared to experimentally determined critical supersaturations.

\section{Theory}

Köhler theory (Köhler, 1936) describes the saturation ratio, $S$, of water vapor over a solution droplet of a given radius, $D_{p}$ :

$$
S=\frac{p}{p_{0}}=a_{\mathrm{w}} \cdot \exp \left(\frac{4 M_{\mathrm{w}} \sigma_{\mathrm{al}}}{R T \rho D_{P}}\right)
$$

where $p$ is the water vapor pressure over the aqueous solution droplet, $p_{0}$ is the water vapor pressure over a flat water surface, $a_{\mathrm{w}}$ is the water activity in the droplet solution, $\sigma_{\mathrm{al}}$ is the air-liquid interfacial surface tension, $M_{\mathrm{W}}$ is the molar mass of water, $R$ is the universal gas constant, $\rho$ is the density of the droplet solution, and $T$ is the absolute temperature (Seinfeld and Pandis, 1998).

The Köhler equation is the product of two effects: The Kelvin effect which describes how curvature increases the vapor pressure of water over an aqueous solution droplet; and the Raoult effect which describes how the concentration of dissolved matter decreases the vapor pressure of water over an aqueous solution droplet. In this work, surface tension and water activity are parameterized as functions of weight percentage of the solutes in bulk aqueous solution. Limited solubility, as discussed by Bilde and Svenningsson (2004), and surfactant partitioning, as described by Li et al. (1998), Sorjamaa et al. (2004), and Prisle et al. (2008), are not accounted for in our calculations, but will be discussed in Sect. 4.3.

Water activity of a solution depends on the concentrations of the various chemical species dissolved in it. High density compounds with low molecular weights and high degrees of dissociation can dissociate into more ions and thus efficiently reduce water activity. However, without experimental data water activity can be difficult to estimate, especially for complex mixtures where the various solutes may interact with solvent and with each other. We here calculate water activity in two ways and compare with experimental data: 
(1) with the state of the art thermodynamic aerosol model, EAIM, (http://www.aim.env.uea.ac.uk/aim/aim.php, Clegg et al., 2001) or (2) by following the approach of e.g. Bilde and Svenningsson (2004) and calculating water activity from the van't Hoff factors of the individual compounds in solution:

$a_{\mathrm{w}}=\frac{n_{\mathrm{w}}}{n_{\mathrm{w}}+\sum_{\mathrm{s}} i_{\mathrm{s}} n_{\mathrm{s}}}$,

where $n_{\mathrm{w}}$ and $n_{\mathrm{S}}$ are the number of moles of water and solutes, respectively, and $i_{\mathrm{s}}$ is the van't Hoff factor of the solute s. The van't Hoff factor is defined as the ratio between the number of moles of species in aqueous solution and the number of moles of substance dissolved, and it is dependent on the concentration of solutes (e.g. Low, 1969). For a binary mixture with the mass ratio $X=m_{1} / m_{2}$ between the two compounds, Eq. (2) can be restated as:

$a_{\mathrm{w}}=\frac{n_{\mathrm{w}}}{n_{\mathrm{w}}+\sum_{\mathrm{s}=1}^{2} i_{\mathrm{s}} n_{\mathrm{s}}}=\frac{n_{\mathrm{w}}}{n_{\mathrm{w}}+i_{1} n_{1}+i_{2} n_{2}}=\frac{n_{\mathrm{w}}}{n_{\mathrm{w}}+i_{t} n_{t}}$,

where $n_{t}$ is the sum of $n_{1}$ and $n_{2}$, the number of moles of the two compounds with molar masses $M_{1}$ and $M_{2}$ and van't Hoff factors $i_{1}$ and $i_{2}$, respectively, and:

$i_{t}=\frac{X \cdot i_{1} \cdot M_{2}+M_{1} \cdot i_{2}}{X \cdot M_{2}+M_{1}}$.

For most non-electrolytes the van't Hoff factor is close to 1 , but for strong acids or electrolytes the van't Hoff factor is typically larger. Van't Hoff factors for a series of inorganic compounds have previously been published (Low, 1969), and van't Hoff factors of monovalent acids in dilute aqueous solution can be estimated from the acid concentration $c_{\mathrm{S}}$ and the acid constant, $K_{\mathrm{a}}$ :

$i_{\mathrm{s}}=1+\frac{-K_{\mathrm{a}}+\sqrt{K_{\mathrm{a}}^{2}+4 K_{\mathrm{a}} \cdot c_{\mathrm{s}}}}{2 c_{\mathrm{s}}}$

This equation can also be used for polyvalent acids if the next dissociation steps are negligible compared to the first, i.e. if the first acid constant, $K_{\mathrm{a} 1}$ is much smaller than the next acid constants, $K_{\mathrm{a} 2}, K_{\mathrm{a} 3}$, etc. (Frosch et al., 2010). For many atmospherically relevant compounds, information about water activity and van't Hoff factors is not available, and simplifications have been made by for example estimating the degree of dissociation in aqueous solution (Kiss and Hansson, 2004).

Water activity has been described by a number of different one-parameter approaches: for example the combined effect of density, molar mass and degree of dissociation on water activity has been described by the so-called ionic density, $\rho_{\text {ion }}$ (Wex et al., 2007). Here we apply the widely used single hygroscopicity parameter, $\kappa$, described by Petters and Kreidenweis (2007):

$\frac{1}{a_{\mathrm{w}}}=1+\kappa \frac{V_{\mathrm{s}}}{V_{\mathrm{w}}}$ where $V_{\mathrm{s}}$ and $V_{\mathrm{w}}$ are the volumes of dry particulate matter and water, respectively. Combining Eqs. (2) and (6), $\kappa$ can be expressed as (Petters and Kreidenweis, 2007):

$\kappa=i \frac{M_{\mathrm{w}}}{M_{\mathrm{s}}} \frac{\rho_{\mathrm{s}}}{\rho_{\mathrm{W}}}$

For multicomponent systems, the overall value of $\kappa$ is given by the simple mixing rule:

$\kappa=\sum_{i} \varepsilon_{i} \kappa_{i}$

where $\varepsilon_{i}$ is the volume fraction, and $\kappa_{i}$ is the single hygroscopicity parameter of component $i$. Rissler et al. (2010) have compared the performance of five such one-parameter approaches including $\kappa$ and the ionic density, $\rho_{\text {ion }}$. To describe solute concentration of aqueous solution droplets up to the point of activation, we employ growth factors, GF, defined in the following way: When a particle with an initial dry diameter, $d_{0}$, takes up water, the diameter will increase to $D_{p}$. This growth can be expressed by the growth factor:

$\mathrm{GF}=D_{p} / d_{0}$

Because GF depends on the amounts of both water and solute, it is also an expression of solute concentration in an aqueous solution. For example, the growth factor is related to the weight percent $(\mathrm{w} / \mathrm{w} \%)$ of solute in solution by

$\mathrm{GF}=\left(1+\frac{p_{\mathrm{s}}}{p_{\mathrm{w}}}\left(\frac{1}{0.01 \cdot \mathrm{w} / \mathrm{w} \%}-1\right)\right)^{1 / 3}$

and to the molality, $b$, by

$\mathrm{GF}=\left(1+\frac{\rho_{\mathrm{s}}}{\rho_{\mathrm{w}} M_{\mathrm{s}}} \frac{1}{b}\right)^{1 / 3}$

where $M_{\mathrm{s}}$ is the effective molar mass of the dry particle, $\rho_{\mathrm{s}}$ and $\rho_{\mathrm{w}}$ are the densities of the dry particle and of water, respectively, and weight percent is with respect to weight of the solution including water (solvent) and all solutes.

In case of solutions containing one organic acid and one inorganic salt the weight percent is defined as

$\mathrm{w} / \mathrm{w} \%=\frac{m_{\mathrm{o}}+m_{\mathrm{i}}}{m_{\mathrm{o}}+m_{\mathrm{i}}+m_{\mathrm{w}}} \cdot 100 \%$,

and the molality as

$b=\frac{n_{\mathrm{o}}+n_{\mathrm{i}}}{m_{\mathrm{w}}}$,

where $m_{\mathrm{w}}, m_{\mathrm{i}}$ and $m_{\mathrm{o}}$ are the masses of water, the inorganic and the organic component, respectively, and $n_{\mathrm{i}}$ and $n_{\mathrm{o}}$ are the number of moles of the organic and inorganic component. The growth factor is determined according to Eq. (10), using a density, $\rho_{\mathrm{s}}$, and a molar mass, $M_{\mathrm{s}}$, calculated as

$\frac{1}{\rho_{\mathrm{s}}}=\frac{X_{\text {organic }}}{\rho_{\text {organic }}}+\frac{1-X_{\text {organic }}}{\rho_{\text {inorganic }}}$, 
$\frac{1}{M_{\mathrm{s}}}=\frac{X_{\text {organic }}}{M_{\text {organic }}}+\frac{1-X_{\text {organic }}}{M_{\text {inorganic }}}$

where $\rho_{\text {organic }}$ and $\rho_{\text {inorganic }}$ are the densities of the organic and inorganic compound, $M_{\text {organic }}$ and $M_{\text {inorganic }}$ are the molar masses of the organic and inorganic, respectively, and $X_{\text {organic }}$ is the mass fraction of the organic compound in the initial dry particle.

In this study, critical supersaturations have been determined for internally mixed particles with diameters between 30 and $100 \mathrm{~nm}$. The growth factors at activation of these particles are in the range $3-12$.

\section{Experimental}

In this study, nine different mixtures between organic acids and the inorganic salts sodium chloride and ammonium sulphate were investigated, see Table 1. Most chemicals for surface tension, osmolality, and CCN measurements were obtained from commercial sources: ammonium sulphate (Sigma-Aldrich, 99.999\%), sodium chloride (RiedeldeHan, 99.8\%), adipic acid (Aldrich, 99\%), citric acid (Aldrich $>99.5 \%$ ), oxalic acid dihydrate (Fluka, > 99.5\%), succinic acid (Fluka, 99.5\%), cis-pinonic acid (Aldrich, 98\%) and used as received. NRFA was purchased from the International Humic Substance Society (http://www.ihss. gatech.edu/index.html). Aqueous solutions were prepared by dissolving chemicals in double-deionized water purified using a MilliQ Plus Ultrapure water system. For solutions containing oxalic acid, 50:50 or 80:20 mixtures were prepared using oxalic acid dihydrate. This means that the mass ratio between oxalic acid (excluding crystal water) and salt is slightly different (42:58 and 74:26 respectively). However, in the following we will refer to these solutions as 50:50 and 80:20.

Measurements of osmolality and surface tension were performed at the University of Pannonia. First, solutions of mixtures with growth factors of relevance to cloud droplet activation $(\mathrm{GF}=2-12)$ were prepared. Osmolality and surface tension measurements were carried out when both the organic and inorganic components were entirely dissolved. Osmolality was measured with a KNAUER K - 7400 Semimicro osmometer. This method considers all of the processes in the solution (e.g. dissociation of solute, interaction between solute and solvent). For one measurement, $0.15 \mathrm{ml}$ solution was used. The measurement time was approximately $2 \mathrm{~min}$; the measuring range was $0-2000 \mathrm{mOsm} \mathrm{kg}^{-1}$. Water activity was calculated from the measured osmolality, as described by Kiss and Hansson (2004). Surface tension of the solutions was measured with an FT 125 tensiometer, which uses pendant drop shape analysis. From one drop of solution, 40 parallel measurements were performed during $10 \mathrm{~s}$ at room temperature. The volume of the droplet was approximately $10 \mu \mathrm{l}$ corresponding to a curvature radius of $1.3 \mathrm{~mm}$.
Critical supersaturations of the mixtures were determined experimentally at the University of Copenhagen. The experimental setup has been described previously (Bilde and Svenningsson 2004; Svenningsson et al., 2006), and is briefly presented here: Aerosol particles were produced from a bulk aqueous solution of the desired chemical composition using a constant output atomizer (TSI, 3076). During aerosol production, the aqueous solution was continuously stirred to ensure a homogeneous distribution of solutes in solution, i.e. prevent the surface active compounds from concentrating in the solution surface. The produced particles are assumed to be internally mixed and have the same chemical composition as in the aqueous solution. The particles were dried in diffusion driers using silica gel and mixed with dried, particle free air. The relative humidity of the aerosol flow was measured several times during the experiments and was always found to be below $12 \%$. A specific particle diameter was selected using a differential mobility analyzer (DMA, TSI 3080) before the aerosol flow was divided between a condensation particle counter (CPC, TSI 3010) and a static thermal diffusion cloud condensation nucleus counter (CCNC, University of Wyoming CCNC-100B). The CPC measured the total concentration of particles, whereas the $\mathrm{CCNC}$ detected the number of activated particles at a specified supersaturation (SS) of water. The supersaturation in the CCNC could be varied stepwise between 0.2 and $2.0 \%$. The critical supersaturation ( $\mathrm{SSc}$ ) was determined using the relaxed step transfer function (Svenningsson and Bilde, 2008) assuming full solubility. The CCNC was calibrated using ammonium sulphate as described by for example Bilde and Svenningsson (2004) using van't Hoff factors from Low (1969) and Young and Warren (1992). Points for the calibration line were obtained both before, during and after the actual experiments were performed. The same calibration was used for all experiments.

\section{Results and discussion}

\subsection{Surface tension}

Surface tension was measured in model solutions of the six 50:50 organic-inorganic mixtures containing ammonium sulphate (measurements at selected weight percentages are shown in Table 2; the full data sets are shown in Fig. 1). For each mixture, best fits were obtained from a wide variety of functions. These are given in Table 3 together with the appropriate concentration range of validity, i.e. the concentration range of the surface tension measurements. No fit is shown for the mixture of oxalic acid dihydrate and ammonium sulphate, because the surface tension depression of these mixtures is negligible. Figure 1 shows the measured surface tensions both as a function of growth factor and of molality (i.e. the total amount of both organic acid and inorganic salt in aqueous solution). 
Table 1. Chemical composition of mixtures which have been used in experiments.

\begin{tabular}{ll}
\hline Mixture & Mass ratio \\
\hline Oxalic acid* (OA) + ammonium sulphate (AS) & $50: 50$ \\
Oxalic acid* (OA) + ammonium sulphate (AS) & $80: 20$ \\
Oxalic acid* (OA) + sodium chloride (SC) & $50: 50$ \\
Oxalic acid* (OA) + sodium chloride (SC) & $80: 20$ \\
Succinic acid (SA) + ammonium sulphate (AS) & $50: 50$ \\
Citric acid (CA) + ammonium sulphate (AS) & $50: 50$ \\
cis-Pinonic acid (cPA) + ammonium sulphate (AS) & $50: 50$ \\
Adipic acid (AA) + ammonium sulphate (AS) & $50: 50$ \\
Nordic reference fulvic acid (NRFA) + ammonium sulphate (AS) & $50: 50$ \\
\hline
\end{tabular}

\footnotetext{
* We here refer to the mass ratio of oxalic acid dihydrate to salt. See text for details on conversion to anhydrous oxalic acid. For details on molar mass and density of anhydrous oxalic acid, we refer to Varga et al. (2007).
}

Table 2. Surface tension $(\sigma)$ as a function of weight percentage (w/w\%) for the mixtures with 50:50 mass ratio between an organic acid and ammonium sulphate (abbreviations are explained in Table 1).

\begin{tabular}{lrrrrrr}
\hline \multirow{2}{*}{ w/w\% } & \multicolumn{7}{c}{$\sigma / \mathrm{mN} \mathrm{m}^{-1}$} \\
\cline { 2 - 7 } & $\begin{array}{r}\text { Oxalic acid } \\
+ \text { AS, } 50: 50\end{array}$ & $\begin{array}{r}\text { Succinic acid } \\
+ \text { AS, 50:50 }\end{array}$ & $\begin{array}{r}\text { Adipic acid } \\
+ \text { AS, 50:50 }\end{array}$ & $\begin{array}{r}\text { Citric acid } \\
+ \text { AS, 50:50 }\end{array}$ & $\begin{array}{r}\text { NRFA } \\
\text { + AS, 50:50 }\end{array}$ & $\begin{array}{r}\text { Cis-pinonic acid } \\
+ \text { AS, 50:50 }\end{array}$ \\
\hline 0.1 & 72 & 72 & 72 & 72 & 70 & 69 \\
0.5 & 72 & 72 & 71 & 72 & 63 & 62 \\
1 & 72 & 71 & 69 & 72 & 61 & 59 \\
2 & - & 71 & - & 72 & - & 56 \\
5 & 72 & 69 & - & 71 & - & - \\
10 & - & - & - & 70 & - & - \\
20 & - & 66 & - & 66 & - & - \\
\hline
\end{tabular}

Table 3. Fitted functions of surface tension and water activity as a function of growth factor $(x=\mathrm{GF})$ for the studied $50: 50$ mixtures containing ammonium sulphate (abbreviations are explained in Table 1).

\begin{tabular}{lllr}
\hline & Surface tension, $\sigma / \mathrm{mN} \mathrm{m}^{-1}$ & Water activity, $a_{\mathrm{W}}$ & Range, $x$ \\
\hline OA + AS & $\sigma=\sigma_{\mathrm{W}}$ & $0.9997 \cdot \exp (-\exp (-2.6047-0.5845 \cdot x))$ & $4-12$ \\
$\mathrm{SA}+\mathrm{AS}$ & $72.3 \cdot \exp (-\exp (-0.850-0.759 \cdot x))$ & $\left(2.139+x^{2.802}\right) /\left(2.464+x^{2.802}\right)$ & $5-11$ \\
$\mathrm{AA}+\mathrm{AS}$ & $72.6-403 \cdot \exp \left(-1.928 \cdot x^{0.542}\right)$ & $0.9996 \cdot \exp (-\exp (-2.805-0.634 \cdot x))$ & $2-12$ \\
$\mathrm{CA}+\mathrm{AS}$ & $72.0 /(1+9.916 \cdot \exp (-2.320 \cdot x))$ & $\left(0.870+x^{3.305}\right) /\left(1.358+x^{3.305}\right)$ & $2-12$ \\
NRFA + AS & $70.2 /\left(1+\exp \left((22.8-2.233 \cdot x)^{0.0159}\right)\right)$ & $0.9998 \cdot \exp (-\exp (-3.20-0.580 \cdot x))$ & $6-12$ \\
$\mathrm{cPA}+\mathrm{AS}$ & $69.9-18.4 \cdot \exp \left(-0.00111-x^{2.406}\right)$ & $\left(2.911+x^{2.714}\right) /\left(3.073+x^{2.714}\right)$ & $3-11$ \\
\hline
\end{tabular}

The mixtures can be separated into three different groups: For the mixtures containing oxalic acid dihydrate, no deviation is seen from the surface tension of pure water. For mixtures containing succinic acid, adipic acid, or citric acid, a slight surface tension depression is observed in the concentration range relevant for activation $(\mathrm{GF}=3-12$ for particles with diameter in the range $30-100 \mathrm{~nm}$ ). And for the remaining two series of mixtures, ammonium sulphate mixed with NRFA and with cis-pinonic acid, respectively, surface ten- sion is significantly lowered. This is a consequence of the fact that both fulvic acid and cis-pinonic acid are effective surfactants (Shulman et al., 1996; Kiss et al., 2005; Varga et al., 2007). The surface tension of pure cis-pinonic acid in aqueous solution is also shown for comparison in Fig. 1. At a given growth factor, the surface tension is lower in a solution of the pure cis-pinonic acid than in a solution containing a mixture (50:50) between cis-pinonic acid and ammonium sulphate. Neglecting the effects of surfactant partitioning, 


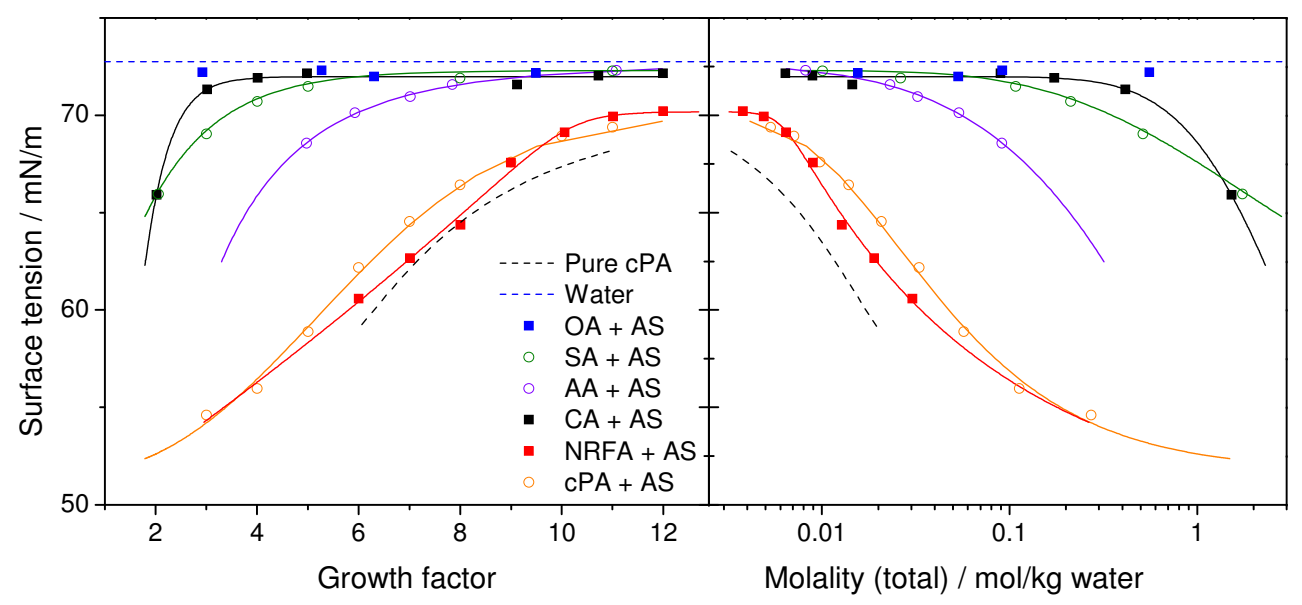

Fig. 1. Measured surface tension of the 50:50 mixtures containing an organic acid and ammonium sulphate (abbreviations are explained in Table 1). Continuous lines based on empirical fits (see Table 3) are included to aid visual inspection. A parameterization of the surface tension of pure cis-pinonic acid in aqueous solution (Varga et al., 2007) is included for comparison.

this means that for example at a concentration corresponding to $\mathrm{GF}=6$ the surface tension of a cis-pinonic acid solution is $59 \pm 0.6 \mathrm{mN} \mathrm{m}^{-1}$ (Varga et al., 2007) whereas it is $62 \pm 0.6 \mathrm{mN} \mathrm{m}^{-1}$ for the solution formed on a mixed particle of the same dry size. This difference in surface tension is caused by ammonium sulphate replacing cis-pinonic acid, resulting in a lower concentration of the surfactant. At GF $=6$ the concentration of cis-pinonic acid in the droplet formed on a mixed particle is $0.252 \mathrm{w} / \mathrm{w} \%$ and using the surface tension data from Tuckermann and Cammenga (2004) or the parametrization from Varga et al. (2007) this concentration leads to a surface tension value of $61-61.5 \pm 0.6 \mathrm{mN} \mathrm{m}^{-1}$. This fits well with the value $\left(62 \pm 0.6 \mathrm{mN} \mathrm{m}^{-1}\right)$ obtained for the mixed solution corresponding to $\mathrm{GF}=6$ (see Fig. 1).

If, instead, the surface tension is depicted as a function of the concentration of only the organic matter (not the concentration of both organic and inorganic compound), a slightly different picture arises (see Fig. 2): now, the same amount of organic surfactant has a similar effect on surface tension in the ternary solution with salt as in the binary solution of cis-pinonic acid and water. Note, that the mass ratio between the organic acid and ammonium sulphate is 50:50. Therefore, when the molality of the organic in aqueous solution increases, the molality of the inorganic salt also increases for all mixtures. This means that if a salting-out effect on surface tension, similar to that reported by e.g. Shulman et al. (1996) and Kiss et al. (2005), could be observed, it should be even more pronounced in solutions with higher molality. For the solutions containing succinic acid, adipic acid, or citric acid, Fig. 2b-d shows that, similarly to the mixtures containing cis-pinonic acid, the surface tension depression as a function of the molality of organic is not changed notably when ammonium sulphate is present. The deviation between this result and observations reported earlier (Shulman et al., 1996; Kiss et al., 2005) can be explained by the difference in the concentration of inorganic salt. Shulman et al. (1996) as well as Kiss et al. (2005) used $2 \mathrm{M}\left(\approx 2 \mathrm{~mol} \mathrm{~kg}^{-1}\right)$ ammonium sulphate to study the enhancement of surface tension depression of organic surfactants. Ammonium sulphate in that concentration can be present in the very early phase of droplet formation (i.e. $\mathrm{GF}<2$ ). However, in our experiments, the molality of ammonium sulphate was significantly lower $\left(<0.15 \mathrm{~mol} \mathrm{~kg}^{-1}\right)$, which is relevant for the conditions around activation. As a consequence, the salting-out effect of ammonium sulphate was not observed, the only exception being the mixture of citric acid and ammonium sulphate for which a solution with $\mathrm{GF}=2$ (corresponding to a molality of $1.5 \mathrm{~mol} \mathrm{~kg}^{-1}$ ) was studied. This solution had a lower surface tension than the corresponding solution containing only citric acid (see Fig. 2d).

We conclude that, under the conditions relevant for cloud droplet activation of aerosol particles, the surface tension depression of droplet solutions formed on 50:50 mixed particles containing surfactants is approximately equal to or slightly lower than that of droplet solutions formed on particles of the same size composed of the corresponding pure organic compound. Note that a lower surface tension depression corresponds to a higher surface tension. Significant enhancement of surface tension depression in the presence of salt compared to pure organic compounds is not observed even when surface tension is depicted as a function of the concentration of the organic compound, i.e. we do not detect any salting-out effect in the concentration range relevant for cloud droplet activation, GF $=3-12$. In the solutions containing oxalic acid, adipic acid, succinic acid and citric acid the surface tension depression at concentrations relevant for activation was small. 

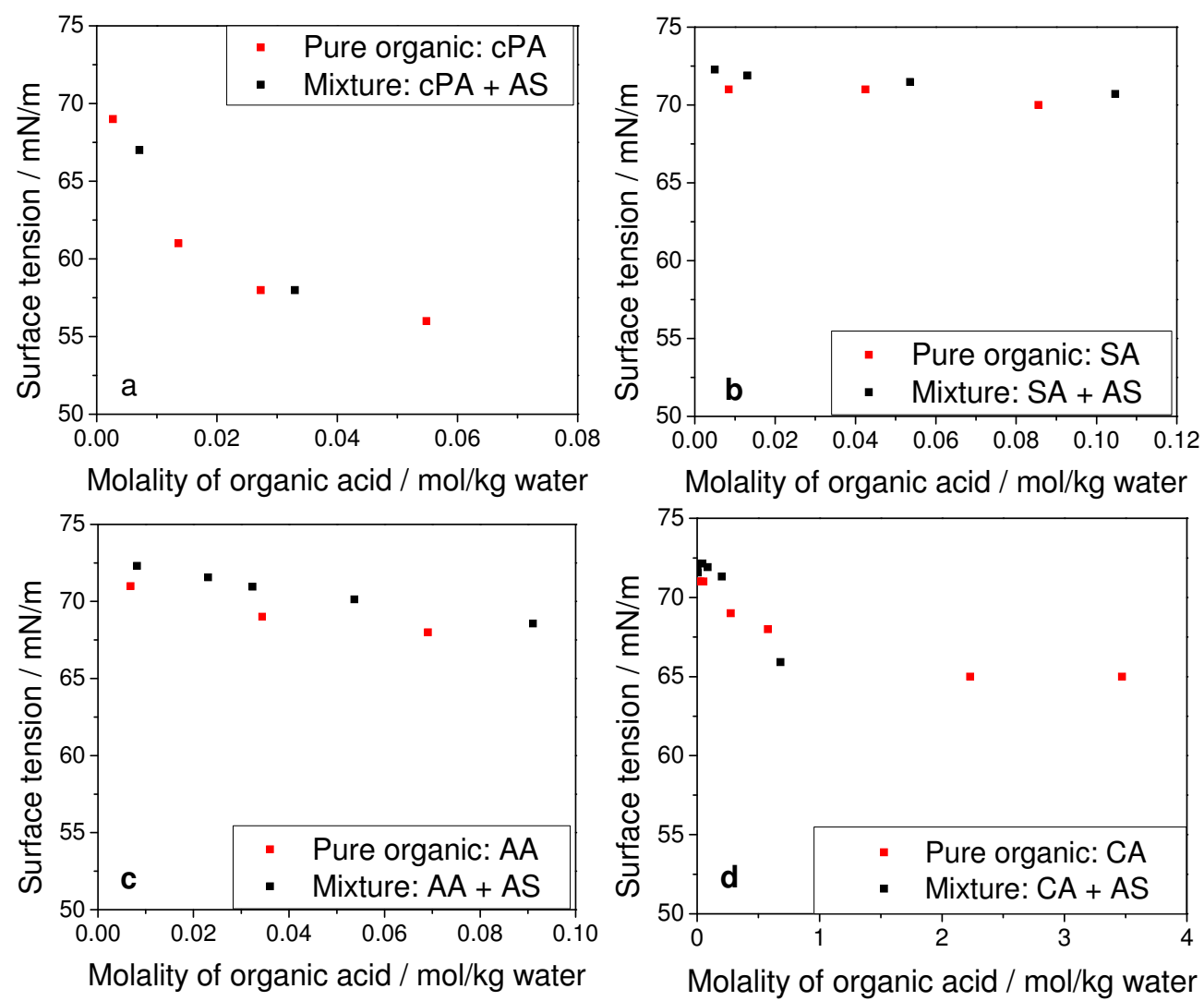

Fig. 2. Measured surface tension for four of the studied 50:50 mixtures (abbreviations are explained in Table 1). The data is depicted as a function of molality of the organic compound in aqueous solution. The data for pure organic acids is obtained from Varga et al. (2007).

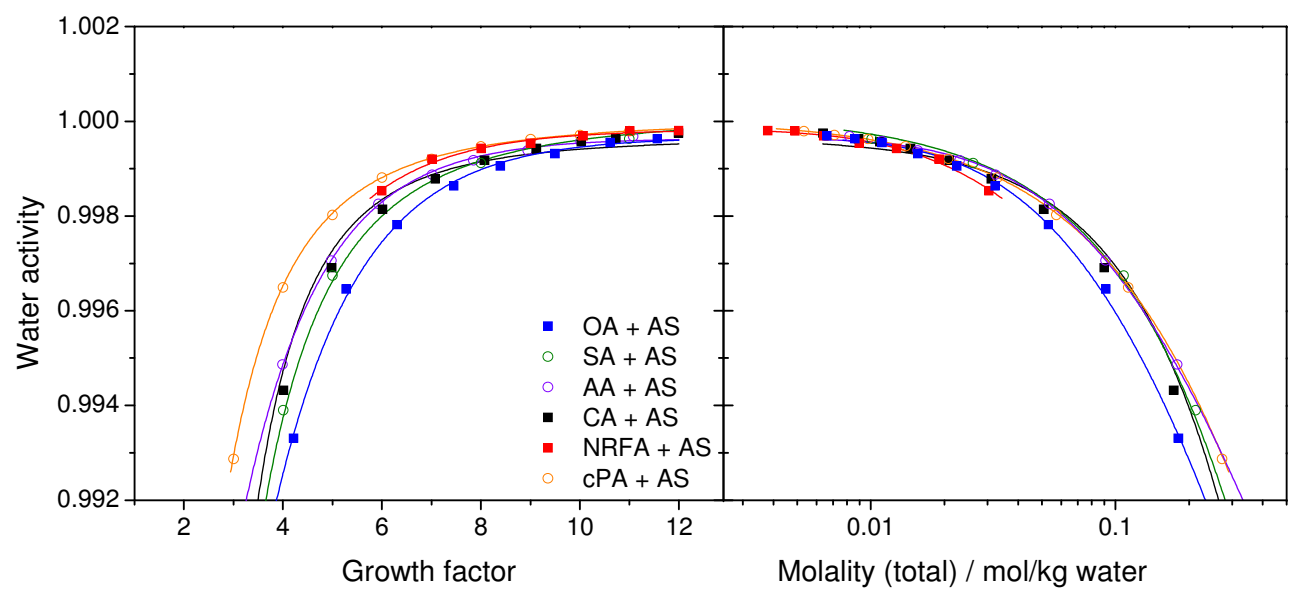

Fig. 3. Measured water activity of the 50:50 mixtures containing an organic acid and ammonium sulphate (abbreviations are explained in Table 1). Continuous lines based on empirical fits (see Table 3) are included to aid visual inspection.

\subsection{Water activity}

Water activity was determined as a function of growth factor and of molality in solutions containing organic acids and ammonium sulphate, see Fig. 3. A best fit was determined for water activity data for each set of solutions, see Table 3 .
Data at selected weight percentages is tabulated in Table 4; for the full data sets, see Fig. 3.

First, mixtures with a 50:50 mass ratio between ammonium sulphate and organic acids will be discussed: High density compounds with low molecular weight and high van't Hoff factor dissociate into more ions at any given growth 
Table 4. Water activity $\left(a_{\mathrm{w}}\right)$ as a function of weight percentage (w/w\%) for the 50:50 mixtures between an organic acid and ammonium sulphate (abbreviations are explained in Table 1).

\begin{tabular}{rrrrrrr}
\hline w/w\% & \multicolumn{6}{c}{$a_{\mathrm{w}}$} \\
\cline { 2 - 7 } & $\begin{array}{r}\text { Oxalic acid } \\
+ \text { AS }\end{array}$ & $\begin{array}{r}\text { Succinic acid } \\
+ \text { AS }\end{array}$ & $\begin{array}{r}\text { Adipic acid } \\
+ \text { AS }\end{array}$ & $\begin{array}{r}\text { Citric acid } \\
+ \text { AS }\end{array}$ & $\begin{array}{r}\text { NRFA } \\
+ \text { AS }\end{array}$ & $\begin{array}{r}\text { Cis-pinonic acid } \\
+ \text { AS }\end{array}$ \\
\hline 0.1 & 0.9997 & 0.9996 & 0.9997 & 0.9997 & 0.9998 & 0.9997 \\
0.5 & 0.9986 & 0.9991 & 0.9989 & 0.9988 & 0.9992 & 0.9988 \\
1 & 0.9971 & 0.9967 & 0.9976 & 0.9975 & 0.9985 & 0.9980 \\
2 & 0.9949 & 0.9939 & - & 0.9956 & - & 0.9965 \\
5 & - & 0.9846 & - & 0.9879 & - & - \\
20 & - & - & - & 0.9571 & - & - \\
\hline
\end{tabular}

Table 5. Physical properties of the studied compounds.

\begin{tabular}{lrrrrrr}
\hline Compunds & $\begin{array}{c}\text { Molar mass } \\
\left(\mathrm{kg} \mathrm{mol}^{-1}\right)\end{array}$ & $\begin{array}{r}\text { Density } \\
\left(\mathrm{kg} \mathrm{m}^{-3}\right)\end{array}$ & $p \mathrm{~K}_{\mathrm{a} 1}$ & \multicolumn{2}{c}{$\kappa_{\text {calc }}^{\mathrm{b}}$} & $\kappa_{\text {lit }}^{\mathrm{c}}$ \\
\hline Sodium chloride & 0.05844 & 2164 & - & 1.25 & 1.27 & $1.28^{\mathrm{d}}$ \\
Ammonium sulphate & 0.13214 & 1769 & - & 0.49 & 0.54 & $0.61^{\mathrm{d}}$ \\
Oxalic acid dihydrate & 0.12607 & 1653 & 1.25 & 0.31 & 0.43 & $0.27-0.36^{\mathrm{e}}$ \\
Succinic acid & 0.11809 & 1572 & 4.21 & 0.24 & 0.25 & $0.17-0.30^{\mathrm{e}}$ \\
Adipic acid & 0.14614 & 1362 & 4.42 & 0.17 & 0.18 & $0.096^{\mathrm{d}}$ \\
Citric acid & 0.19212 & 1665 & 3.13 & 0.16 & 0.19 & N.A. \\
cis-Pinonic acid & 0.18423 & 786 & $\sim 7$ & 0.077 & 0.077 & $0.06-0.10^{\mathrm{e}}$ \\
NRFA $^{\mathrm{a}}$ & 2.18 & $\sim 1500$ & $\sim 7$ & 0.012 & 0.013 & N.A. \\
\hline
\end{tabular}

a Molar mass of NRFA from Persson et al. (2000), the density and acidity constants of NRFA are arbitrary estimates.

${ }^{\mathrm{b}}$ Calculated according to Eq. (7) where the van't Hoff factor, $i$, of the organic acids has been determined from Eq. (5) using the first acid constant, and the van't Hoff factor of the inorganic salts has been estimated from the data of Low (1969) and Young and Warren (1992).

${ }^{\mathrm{c}} \mathrm{CCN}$ derived $\kappa$ reported in literature (growth factor derived $\kappa$ values are also available; sources are specified in footnotes below).

d Petters and Kreidenweis (2007).

e Petters et al. (2009).

factor and most efficiently reduce water activity. As a measure of the ability of each studied compound to lower water activity, $\kappa$ is calculated according to Eq. (7) at two different growth factors $(\mathrm{GF}=3$ and $\mathrm{GF}=9$, see Table 5). $\kappa$ has also been reported in literature (e.g. Petters and Kreidenweis, 2007; Petters et al., 2009; Sullivan et al., 2009), but since $\kappa$ can vary with solute concentration (Petters and Kreidenweis, 2007), it is important to compare $\kappa$ for different compounds at the same concentration, and some variation is expected between the calculated and reported $\kappa$ values. Oxalic acid is a relatively strong electrolyte and has similar density and molecular weight as ammonium sulphate. Although estimated $\kappa$ values for oxalic acid dihydrate are lower than for ammonium sulphate, Fig. 4a shows that mixtures of oxalic acid dihydrate and ammonium sulphate have an only slightly lower effect on water activity as pure ammonium sulphate. Ammonium sulphate as well as oxalic acid dihydrate has negligible effect on the surface tension in dilute solutions (Low, 1969; Varga et al., 2007), and also the 50:50 mixture of ammonium sulphate and oxalic acid dihydrate has a neg- ligible effect on surface tension at activation conditions, as concluded in Sect. 4.1. Therefore, particles composed of a mixture of oxalic acid dihydrate and ammonium sulphate are expected to have a similar Kelvin term as particles composed of either pure oxalic acid dihydrate or pure ammonium sulphate. Consequently, both particles composed of mixtures of oxalic acid dihydrate and ammonium sulphate and pure oxalic acid dihydrate particles are expected to activate similarly to pure ammonium sulphate particles. This hypothesis will be further elaborated on in Sect. 4.3.

Next, we proceed to another series of experiments also displayed in Fig. 4, in which the effects of the ratio of the organic acid to inorganic salt and the importance of the type of inorganic salt (ammonium sulphate versus sodium chloride) on water activity were studied. Four types of mixtures were prepared: Oxalic acid dihydrate mixed with either ammonium sulphate or sodium chloride with a mass ratio of either 50:50 or 80:20. Water activities of these solutions are shown in Fig. 4a-b. Figure 4a shows that the measured water activities of 50:50 mixtures of oxalic acid dihydrate and 

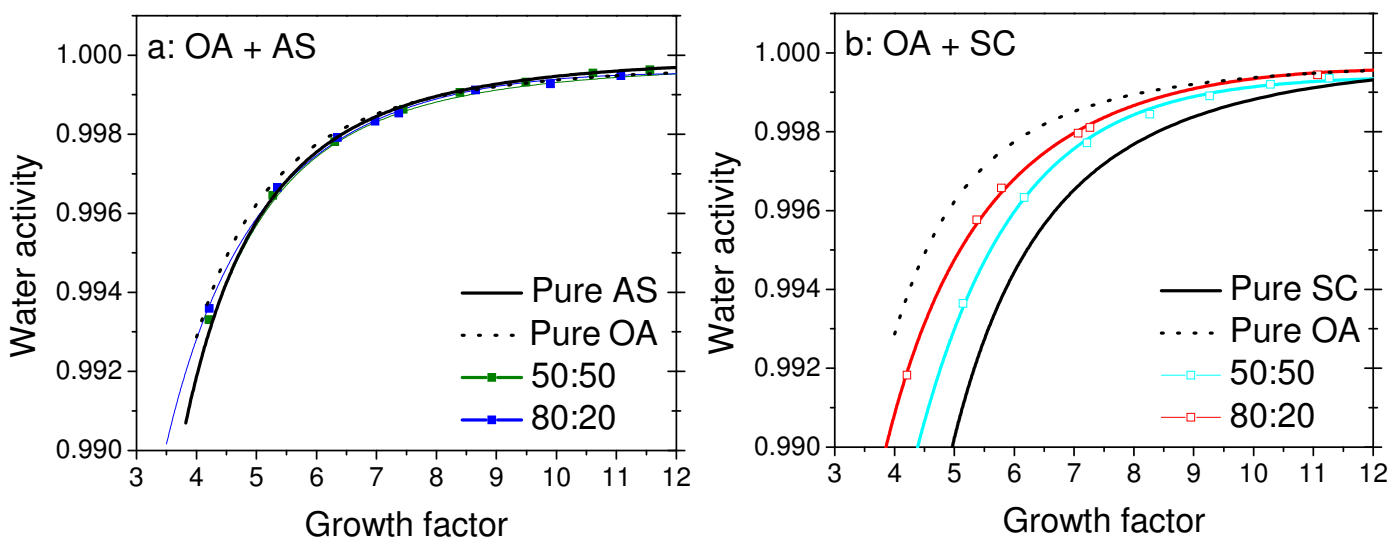

Fig. 4. (a) Measured water activity and fitted functions for the two mixtures containing oxalic acid dihydrate (OA) and ammonium sulphate (AS). (b) Measured water activity and fitted functions for the two mixtures containing oxalic acid dihydrate and sodium chloride (SC). The data is compared to water activities of ammonium sulphate or sodium chloride (Low, 1969; Young and Warren, 1992) and oxalic acid (based on Varga et al., 2007).

ammonium sulphate are similar to the 80:20 mixtures of oxalic acid dihydrate and ammonium sulphate. Both sets of measurements are also close to the water activities of pure ammonium sulphate solutions, reported by Low (1969). This is not the case for the mixtures of sodium chloride and oxalic acid dihydrate. The higher density and lower molecular weight of sodium chloride result in $\kappa$ values of 1.25 and 1.27 at concentrations corresponding to $\mathrm{GF}=3$ and 9 , respectively (see Table 5), and a lower water activity at a given growth factor in aqueous solutions of pure sodium chloride than in mixtures of oxalic acid and ammonium sulphate. The mixture with the higher content of sodium chloride (the 50:50 mixture, light blue squares) lowers water activity the most.

The effect of the type and amount of the inorganic component on water activity is also significant for mixtures containing organic compounds which have a lower $\kappa$ value than oxalic acid dihydrate (e.g. weaker acids or compounds with low water solubility, lower density or higher molar mass). This can be seen in Fig. 5a by comparing the water activity for pure citric acid to the 50:50 mixtures of citric acid and ammonium sulphate. The water activity of a solution containing only citric acid is higher than the water activity of a solution composed of a 50:50 mixture with ammonium sulphate for all concentrations. As seen from Table 5, at a given growth factor, all organic compounds have a lower $\kappa$ value than ammonium sulphate. Therefore, when the mass ratio of ammonium sulphate increases, for example from 0 to $50 \%$, the number of dissociated molecular species increases, and the water activity decreases. This is also the case for the remaining organic acids investigated in this study, see Fig. 5bd. This can have a great effect on $\mathrm{CCN}$ activity since the saturation ratio is directly proportional to the water activity, see Eq. (1). For example, Fig. 3 and the parameterization in Table 3 shows that at $\mathrm{GF}=4$ (corresponding to a total molality of $\left.0.2 \mathrm{~mol} \mathrm{~kg}^{-1}\right), a_{\mathrm{w}}=0.995$ for the $50: 50$ mixture be- tween citric acid and ammonium sulphate. Varga et al. (2007) reports that at the same growth factor, $a_{\mathrm{w}}=0.997$ for pure citric acid. Using Eq. (1) (assuming the surface tension to equal that of pure water), it can be calculated that a critical concentration of $\mathrm{GF}=4$ corresponds to a critical saturation ratio of 1.011 for the 50:50 mixture and 1.013 for pure citric acid. Thus, a $0.2 \%$ difference in water activity will lead to a $\sim 20 \%$ difference in supersaturation (from $1.1 \%$ to $1.3 \%$ ).

Figures 4 and 5 illustrate that the type and relative quantity of the inorganic component has a significant effect on the water activity of an aqueous solution droplet and thereby on activation. In Fig. 5, the measured water activities are also compared to predictions from the E-AIM model and from calculations using estimated van't Hoff factors, see Eq. (3). The van't Hoff factors were determined according to Eq. (4) in two different ways; either calculated as a function of the concentration of the individual species (using Eq. (5) and literature data reported by Low, 1969 and Young and Warren, 1992), or by assuming that the inorganic salt is fully dissociated and that the organic is not dissociated, independently of the solute concentration.

Of the four mixtures displayed in Fig. 5, the greatest deviations between calculated and measured water activity are observed for mixtures containing citric acid. The consequences of these deviations are explored further in Fig. 6, where two examples of Köhler curves are displayed calculated according to Eq. (1). The water activity is based on either measurements, results from E-AIM or from estimated van't Hoff factors for two dry particle diameters, $d_{0}=35$ and $100 \mathrm{~nm}$. For simplicity, the red curves in Fig. 6 are calculated using constant van't Hoff factors ( $i=1$ for organics, and $i=3$ for ammonium sulphate). Figure 6 a shows that for $d_{0}=35 \mathrm{~nm}$, the critical supersaturation is $1.00 \%$ using measured water activity, $0.92 \%$ using E-AIM results and $0.87 \%$ using estimated van't Hoff factors. The critical supersaturation of a $35 \mathrm{~nm}$ 

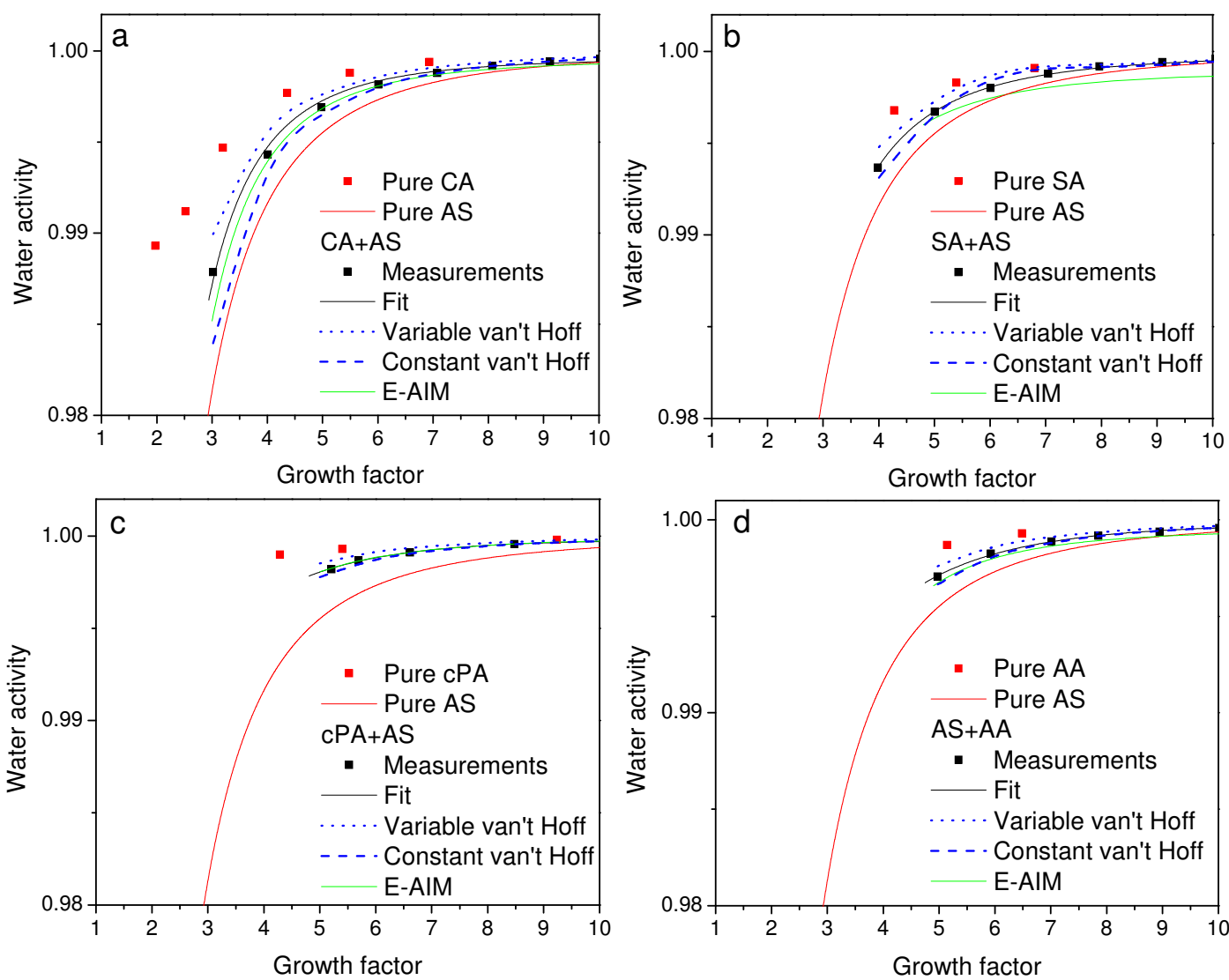

Fig. 5. Water activity of four of the studied 50:50 mixtures (abbreviations are explained in Table 1). The data for pure acids is obtained from Varga et al. (2007). Also shown are water activity determined from the E-AIM and calculated using estimated van't Hoff factors (see Eq. 4). The van't Hoff factors of the individual compounds are either dependent on solute concentrations (using Eq. (5) for organic acids, and the data of Low (1969) and Young and Warren, (1992) for ammonium sulphate) or assumed to be constant ( $i=1$ for the organic acids, and $i=3$ for ammonium sulphate).
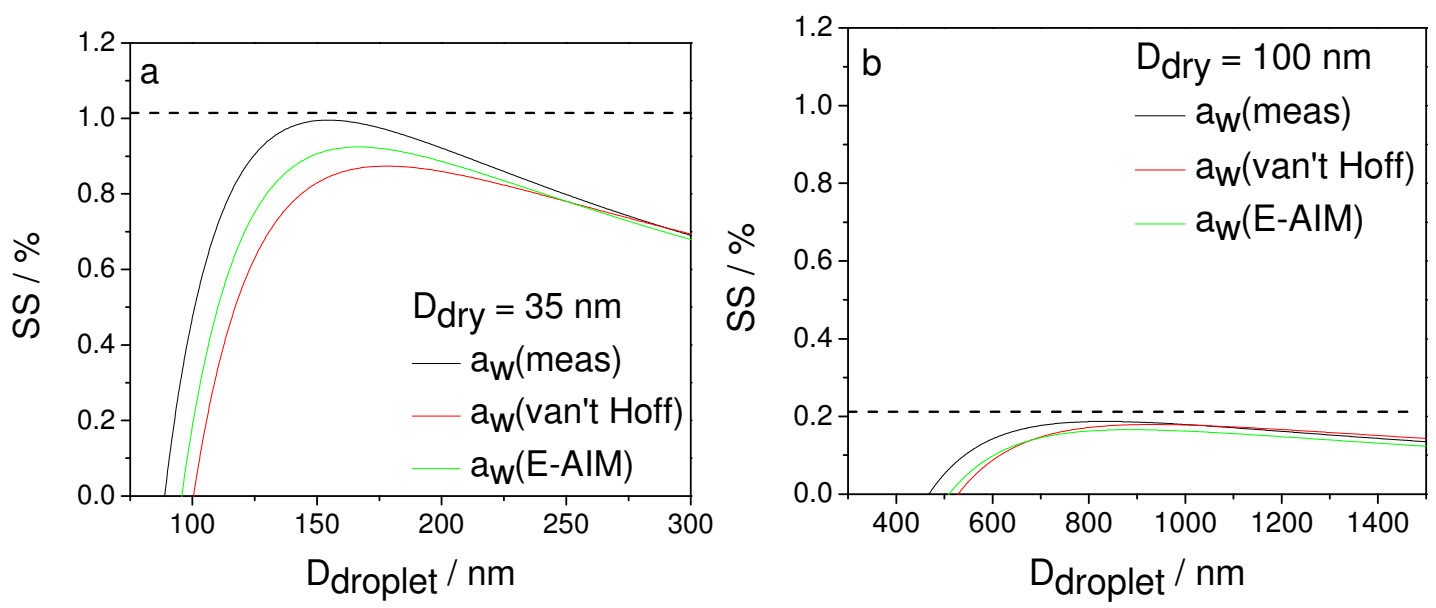

Fig. 6. Köhler curves for 50:50 mixtures of citric acid and ammonium sulphate calculated using a water activity based on either measured water activites, constant van't Hoff factors or modeled results from the E-AIM for two different dry particle diameters, $D_{\text {dry }}$. The surface tension is calculated according to the parameterization in Table 3. The dashed line indicates the critical supersaturation measured with CCNC, listed in Table 6. (a) $D_{\text {dry }}=35 \mathrm{~nm}$ and (b) $D_{\text {dry }}=100 \mathrm{~nm}$. 
particle, which has also been measured with CCNC (these results are presented in Sect. 4.3 and Table 6), is $1.01 \%$. This is indicated by a dashed line. In Fig. $6 \mathrm{~b}, d_{0}=100 \mathrm{~nm}$ and the critical supersaturation is $0.19 \%$ using measured water activity, $0.17 \%$ using E-AIM results and $0.18 \%$ using estimated van't Hoff factors. For comparison, the critical supersaturation measured with CCNC is $0.21 \%$.

From this example it is seen that the deviation in predicted critical supersaturation related to using calculated water activity instead of a parameterization of measurements is large for smaller dry particle diameters (corresponding to more concentrated solution droplets), and less for larger dry particle diameters (corresponding to less concentrated solution droplets).

\subsection{Critical supersaturations}

When the Raoult and Kelvin effects are known, Köhler curves can be calculated according to Eq. (1) for a particle of a given dry size. Critical supersaturations have thus been determined for mixed particles with a dry size between $25 \mathrm{~nm}$ and $110 \mathrm{~nm}$, using $T=298.15 \mathrm{~K}$ and $\rho=\rho_{\mathrm{w}}$, i.e. the aqueous solution density is equated to the density of pure water at room temperature. These results are depicted in Figs. 79. The lines in the figures represent the calculated results based on surface tension and osmolality measurements (parameterizations shown in Table 3) while the individual data points (listed in Table 6) are measured values of the critical supersaturation. For the smallest particle diameters, surface tension and water activity parameterizations have been extrapolated outside the validity ranges given in Table 3. In Figs. 7-9, the extrapolated sections are indicated by dashed lines. Critical diameters and growth factors have been determined for the highest and lowest investigated dry particle diameters and are listed in Table 7, together with $\kappa$ values derived from measurements and estimated $\kappa$ values. $\kappa_{\text {meas }}$ is calculated from the data in Table 6. The average and standard deviation of $\kappa$ are listed together with $\kappa$ determined for the two dry particle diameters, listed in the second column. $\kappa_{\text {calc }}$ is determined using Eq. (7) for activating particles of the same dry size (e.g. at the growth factors, listed in the fourth column). Finally, $\kappa_{\text {est }}$ is estimated from the $\kappa_{\text {lit }}$ values reported from literature listed in Table 5, using Eq. (8). If a range is given in Table 5, a minimum and maximum $\kappa$ has been estimated from the minimum and maximum values of $\kappa_{\text {lit }}$ in Table 5.

Figure 7 shows activation of the oxalic acid dihydrate mixtures. Since neither oxalic acid dihydrate nor the inorganic salts affect surface tension of the droplet solution significantly, water activity in the aqueous solution droplets should be the factor determining critical supersaturation. Consequently, according to the water activity curves in Fig. 4, Köhler theory predicts that particles composed of mixtures of oxalic acid dihydrate and sodium chloride with mass ratio 50:50 should activate most easily, followed by oxalic acid di-
Table 6. Measured critical supersaturation as a function of dry particle diameter for the studied mixtures (abbreviations are explained in Table 1).

\begin{tabular}{cccccccc}
\hline \multicolumn{2}{c}{$\mathrm{OA}+\mathrm{AS}$} & \multicolumn{2}{c}{$\mathrm{OA}+\mathrm{AS}$} & \multicolumn{2}{c}{$\mathrm{OA}+\mathrm{SC}$} & \multicolumn{2}{c}{$\mathrm{OA}+\mathrm{SC}$} \\
\hline \multicolumn{2}{c}{$50: 50$} & \multicolumn{2}{c}{$80: 20$} & \multicolumn{2}{c}{$50: 50$} & \multicolumn{2}{c}{$80: 20$} \\
$d_{0} / \mathrm{nm}$ & $\mathrm{SS}_{\mathrm{c}} / \%$ & $d_{0} / \mathrm{nm}$ & $\mathrm{SS}_{\mathrm{c}} / \%$ & $d_{0} / \mathrm{nm}$ & $\mathrm{SS}_{\mathrm{cc}} / \%$ & $d_{0} / \mathrm{nm}^{2}$ & $\mathrm{SS}_{\mathrm{c}} / \%$ \\
\hline 31 & 1.08 & 35 & 0.85 & 30 & 0.96 & 45 & 1.11 \\
33 & 0.96 & 40 & 0.69 & 31 & 0.90 & 47 & 0.76 \\
35 & 0.85 & 42 & 0.67 & 33 & 0.82 & 50 & 0.58 \\
38 & 0.76 & 44 & 0.61 & 35 & 0.76 & 52 & 0.56 \\
40 & 0.70 & 45 & 0.56 & 37 & 0.65 & 60 & 0.40 \\
45 & 0.61 & 46 & 0.60 & 40 & 0.60 & 65 & 0.37 \\
50 & 0.50 & 48 & 0.54 & 42 & 0.56 & 70 & 0.32 \\
55 & 0.43 & 50 & 0.51 & 45 & 0.54 & 75 & 0.28 \\
60 & 0.37 & 60 & 0.40 & 50 & 0.45 & 80 & 0.27 \\
65 & 0.35 & 70 & 0.31 & 55 & 0.40 & 85 & 0.23 \\
70 & 0.30 & 80 & 0.24 & 60 & 0.36 & 90 & 0.23 \\
75 & 0.29 & 90 & 0.23 & 65 & 0.30 & 95 & 0.20 \\
80 & 0.25 & & & 70 & 0.30 & 100 & 0.22 \\
90 & 0.22 & & & 80 & 0.23 & & \\
95 & 0.22 & & & 88 & 0.20 & & \\
& & & & 95 & 0.15 & & \\
\hline
\end{tabular}

Table 6. Continued.

\begin{tabular}{rrrrrrrr}
\hline \multicolumn{2}{c}{$\mathrm{AA}+\mathrm{AS}$} & \multicolumn{2}{c}{$\mathrm{CA}+\mathrm{AS}$} & \multicolumn{2}{c}{$\mathrm{NRF}+\mathrm{AS}$} & \multicolumn{2}{c}{$\mathrm{SA}+\mathrm{AS}$} \\
\hline \multicolumn{2}{c}{$50: 50$} & \multicolumn{2}{c}{$50: 50$} & \multicolumn{2}{c}{$50: 50$} & \multicolumn{2}{c}{$50: 50$} \\
$d_{0} / \mathrm{nm}$ & $\mathrm{SS}_{\mathrm{c}} / \%$ & $d_{0} / \mathrm{nm}$ & $\mathrm{SS}_{\mathrm{c}} / \%$ & $d_{0} / \mathrm{nm}$ & $\mathrm{SS}_{\mathrm{c}} / \%$ & $d_{0} / \mathrm{nm}$ & $\mathrm{SS}_{\mathrm{c}} / \%$ \\
\hline 33 & 1.06 & 35 & 1.01 & 35 & 1.12 & 30 & 1.15 \\
35 & 1.04 & 37 & 0.92 & 38 & 1.00 & 31 & 1.07 \\
37 & 0.98 & 38 & 0.94 & 38 & 1.03 & 33 & 0.99 \\
38 & 0.92 & 40 & 0.94 & 40 & 1.04 & 35 & 0.88 \\
40 & 0.81 & 42 & 0.77 & 42 & 0.85 & 37 & 0.87 \\
45 & 0.77 & 47 & 0.66 & 42 & 1.02 & 39 & 0.76 \\
47 & 0.70 & 52 & 0.56 & 45 & 0.79 & 41 & 0.73 \\
50 & 0.65 & 57 & 0.49 & 45 & 0.90 & 44 & 0.64 \\
52 & 0.54 & 55 & 0.55 & 47 & 0.74 & 47 & 0.57 \\
55 & 0.60 & 60 & 0.44 & 50 & 0.74 & 50 & 0.53 \\
57 & 0.48 & 62 & 0.42 & 52 & 0.62 & 55 & 0.44 \\
60 & 0.45 & 65 & 0.42 & 55 & 0.58 & 60 & 0.38 \\
60 & 0.49 & 67 & 0.37 & 60 & 0.54 & 65 & 0.34 \\
65 & 0.44 & 75 & 0.34 & 65 & 0.46 & 70 & 0.33 \\
70 & 0.37 & 85 & 0.29 & 70 & 0.44 & 75 & 0.30 \\
75 & 0.32 & 95 & 0.22 & 75 & 0.36 & 80 & 0.26 \\
80 & 0.30 & 100 & 0.21 & 80 & 0.36 & 85 & 0.23 \\
85 & 0.26 & & & 85 & 0.30 & 90 & 0.22 \\
90 & 0.25 & & & 90 & 0.32 & 95 & 0.20 \\
95 & 0.24 & & & 95 & 0.27 & 100 & 0.20 \\
100 & 0.21 & & & & & & \\
\hline
\end{tabular}

hydrate and sodium chloride with mass ratio 80:20 while the two mixtures of oxalic acid dihydrate with ammonium sulphate should activate at the highest but practically identical supersaturation levels. Measured critical supersaturations of the two series of mixtures containing oxalic acid dihydrate and ammonium sulphate were very similar although slightly 
Table 7. Droplet diameter $\left(D_{p \mathrm{c}}\right)$ and growth factor $\left(\mathrm{GF}_{\mathrm{c}}\right)$ at activation for two different dry sizes $\left(D_{\text {dry }}\right)$ as well as measured $\kappa_{\text {values }}$ $\left(\kappa_{\text {meas }}\left(D_{\text {dry }}\right)\right.$, determined from experimental data listed in Table 6 at the two dry particle diameters listed in the second column, $D_{\text {dry }}$, and $\kappa_{\text {meas }}$, determined as the average of all $\kappa$ values calculated from each of the activation experiments listed in Table 6 ), calculated $\kappa$ values $\left(\kappa_{\text {calc }}\right.$, calculated according to Eq. (7), determining $i$ using Eqs. (4) and (5) at the growth factors listed in the fourth column, $\left.\mathrm{GF}_{\mathrm{c}}\right)$ and estimated $\kappa$ values ( $\kappa_{\text {est }}$, estimated by applying Eq. (8) to the $\kappa_{\text {lit }}$ values listed in Table 5).

\begin{tabular}{|c|c|c|c|c|c|c|c|}
\hline Mixture & $\begin{array}{r}D_{\text {dry }} \\
\mathrm{nm}\end{array}$ & $\begin{array}{r}D_{p \mathrm{c}} \\
\mathrm{nm}^{\text {a }}\end{array}$ & $\mathrm{GF}_{\mathrm{c}}$ & $\begin{array}{r}\kappa_{\text {meas }}\left(D_{\text {dry }}\right)^{\mathrm{b}} \\
\kappa_{\text {meas }}\left(D_{\text {dry }}\right)\end{array}$ & $\kappa_{\text {meas }}$ & $\begin{array}{l}\kappa_{\text {calc }}\left(D_{\text {dry }}\right) \\
\kappa_{\text {calc }}\left(D_{\text {dry }}\right)\end{array}$ & $\kappa_{\text {est }}$ \\
\hline $\mathrm{OA}+\mathrm{AS}$ & 31 & 108 & 3.5 & 0.41 & $0.43 \pm 0.04$ & 0.36 & $0.43-0.48$ \\
\hline $50: 50$ & 95 & 800 & 8.4 & 0.33 & & 0.43 & \\
\hline $\mathrm{OA}+\mathrm{AS}$ & 35 & 158 & 4.5 & 0.38 & $0.44 \pm 0.03$ & 0.41 & $0.33-0.41$ \\
\hline $80: 20$ & 90 & 753 & 8.4 & 0.49 & & 0.43 & \\
\hline $\mathrm{OA}+\mathrm{SC}$ & 30 & 175 & 5.8 & 0.47 & $0.57 \pm 0.06$ & 0.63 & $0.71-0.76$ \\
\hline $50: 50$ & 95 & 899 & 9.5 & 0.66 & & 0.65 & \\
\hline $\mathrm{OA}+\mathrm{SC}$ & $50^{\mathrm{f}}$ & 356 & 7.1 & 0.30 & $0.38 \pm 0.04^{b}$ & 0.49 & $0.43-0.51$ \\
\hline $80: 20$ & 100 & 882 & 8.8 & 0.43 & & 0.50 & \\
\hline $\mathrm{SA}+\mathrm{AS}$ & 30 & 134 & 4.5 & 0.35 & $0.40 \pm 0.03$ & 0.40 & $0.38-0.45$ \\
\hline $50: 50$ & 100 & 810 & 8.1 & 0.45 & & 0.42 & \\
\hline $\mathrm{CA}+\mathrm{AS}$ & 35 & 238 & 4.8 & 0.27 & $0.31 \pm 0.03$ & 0.31 & N.A. \\
\hline $50: 50$ & 100 & 643 & 6.4 & 0.34 & & 0.33 & \\
\hline $\mathrm{cPA}+\mathrm{AS}$ & 30 & 101 & 3.4 & - & - & 0.22 & $0.23-0.26$ \\
\hline $50: 50$ & 100 & 773 & 7.7 & - & & 0.24 & \\
\hline $\mathrm{AA}+\mathrm{AS}$ & 33 & 100 & 3.0 & 0.23 & $0.30 \pm 0.03$ & 0.33 & 0.32 \\
\hline $50: 50$ & 100 & 736 & 7.4 & 0.35 & & 0.36 & \\
\hline $\mathrm{NRFA}+\mathrm{AS}$ & 35 & 174 & 5.0 & 0.19 & $0.23 \pm 0.03$ & 0.27 & N.A. \\
\hline $50: 50$ & 95 & 761 & 8.0 & 0.26 & & 0.29 & \\
\hline
\end{tabular}

${ }^{\text {a }}$ Critical diameter is calculated from Eq. (1), using the parameterization shown in Table 3.

$\mathrm{b}$ The measurements at 45 and $47 \mathrm{~nm}$ (see Table 6) are considered outliers and omitted.

higher than predicted by Köhler theory. The CCNC results for the oxalic acid dihydrate and sodium chloride 50:50 mixture were the lowest, which is in agreement with the water activity curves, whereas the CCNC results of mixed particles of oxalic acid dihydrate and sodium chloride in the mass ratio 80:20 deviated significantly from Köhler theory. For example, a dry particle with diameter $60 \mathrm{~nm}$ is predicted to activate at a supersaturation of $0.31 \%$, but is found to activate at $0.40 \%$, corresponding to an underprediction of $29 \%$. This will be discussed below. These deviations are also reflected in the differences between the measured and calculated values of $\kappa$ for the particles containing oxalic acid dihydrate (see Table 7).

The mixed particles containing either one of the three other organic weak surfactants (citric acid, adipic acid, and succinic acid, respectively) and ammonium sulphate activate at higher supersaturations than the mixtures with oxalic acid dihydrate (see Fig. 8) because these organic compounds have a weaker effect on water activity than oxalic acid dihydrate. None of these acids have a strong effect on surface tension at activation and thus water activity is expected to be the dominant factor in determining the critical supersaturation.
For the mixtures containing citric acid and ammonium sulphate (black symbols), in most cases the deviations between measured data and the Köhler curve are within experimental error, whereas the difference between modeled and measured critical supersaturations for particles composed of succinic acid and ammonium sulphate (blue symbols) is somewhat larger, and it is considerable for particles composed of adipic acid and ammonium sulphate (red symbols). For example, a particle with diameter $60 \mathrm{~nm}$ should activate at $0.40 \%$ according to Köhler theory, but is measured to have a critical supersaturation of $0.49 \%$, corresponding to an underprediction of $23 \%$. For these particles, using the surface tension of pure water in the Kelvin term of the Köhler equation results in better agreement with experimental data (red dotted line, yielding a critical supersaturation of $0.42 \%$ for a $60 \mathrm{~nm}$ particle). In the calculated Köhler curves surface tension depression is accounted for, but the effects of partitioning are neglected. The possible effect of surfactant partitioning will be discussed below. The deviations between $\kappa_{\text {calc }}$ and $\kappa_{\text {meas }}$ (see Table 7) are within experimental uncertainty for the three mixtures, and the agreement with reported data $\left(\kappa_{\text {est }}\right)$ is good. 


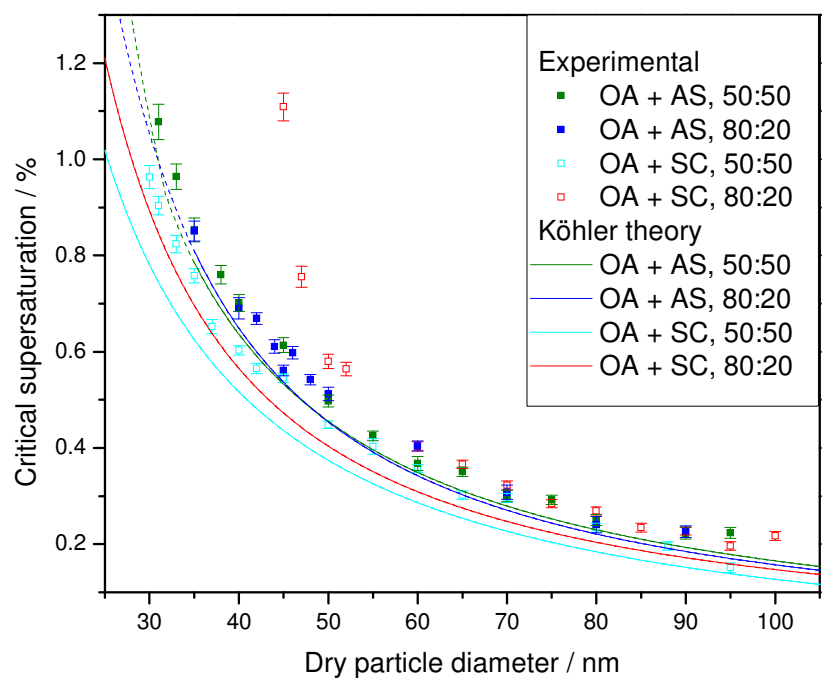

Fig. 7. Comparison between critical supersaturation measured with CCNC and calculated Köhler theory based on measured water activity and the surface tension of water for the four mixtures containing oxalic acid (abbreviations are explained in Table 1). The dashed sections indicate that the parameterizations of water activity are based on extrapolation.

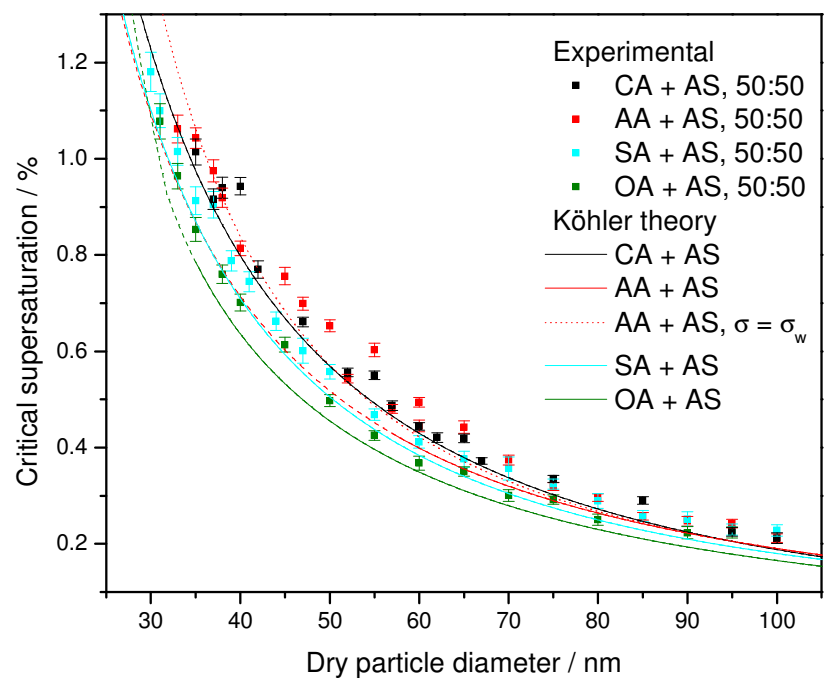

Fig. 8. Comparison between critical supersaturation measured with CCNC and calculated Köhler theory based on measured water activity and surface tension for the 50:50 mixtures containing the slightly surface active organic compounds and ammonium sulphate (abbreviations are explained in Table 1). The dashed sections indicate that the parameterizations of water activity and/or surface tension are based on extrapolation.

In contrast to the organic acids discussed above, both NRFA and cis-pinonic acid have a strong effect on surface tension. In Fig. 9, Köhler theory predicts that these mixtures should activate as easily as the mixtures containing oxalic acid dihydrate and ammonium sulphate. The low critical su-

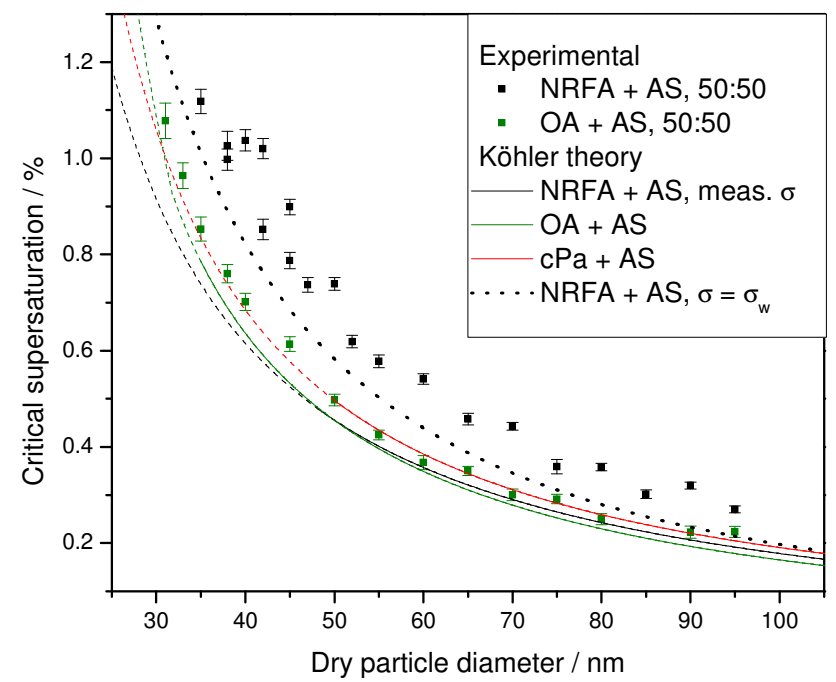

Fig. 9. Comparison between critical supersaturation measured with CCNC and calculated Köhler theory based on measured water activity and surface tension for mixtures containing the most surface active organic compounds (abbreviations are explained in Table 1). The dashed sections indicate that the parameterizations of water activity and surface tension are/or based on extrapolation.

persaturation is related to the strong depression of surface tension. Mixed particles containing cis-pinonic acid and ammonium sulphate proved difficult to study experimentally, and critical supersaturations for these mixed particles are not reported. However, measurements show that particles containing NRFA activates at a supersaturation much higher ( $0.54 \%$ for a $60 \mathrm{~nm}$ particle) than predicted by Köhler theory $(0.35 \%$ for a $60 \mathrm{~nm}$ particle, corresponding to a deviation of $54 \%$ ) using a parameterization of surface tension based on measurements, but neglecting partitioning. For comparison, a Köhler curve is re-calculated using the surface tension of water which gives a better agreement with measured critical supersaturation $(0.46 \%$ for a $60 \mathrm{~nm}$ particle). This is also in concordance with the conclusions of Prisle et al. (2008).

There are several ways to account for deviations between measured and modeled critical supersaturation. One possible explanation is that particles partially evaporated before entering the CCNC, but after size selection in the DMA. In that case, the particles would activate with more difficulty because of their smaller size, and the measured critical supersaturations would be overestimated. Such an effect has been observed for example for glutaric acid particles (Frosch et al., 2010). However, all experiments were performed at room temperature, and the residence time in the tubing and instruments between size selection and activation was approximately 1-2 s. None of the investigated organic compounds should evaporate significantly at room temperature on this time scale (e.g. Yaws, 1994; Bilde and Pandis, 2001; Bilde et al., 2003), and no sign of significant evaporation was observed during experiments. 
It is also possible that activation and droplet growth were limited because of low solubility of the components of the aerosol particles. Although all of the investigated compounds are fairly water soluble, it is well known that the presence of inorganic salts can diminish the solubility of organic compounds (e.g. Streng, 2001; Hefter and Tomkins, 2003). If the particle is not fully soluble, a core of solid material will remain at activation and less solute will be in the aqueous solution droplet (Bilde and Svenningsson, 2004; Broekhuizen et al., 2004a; Kristensson et al., 2010). This will influence both the water activity and surface tension, and it can lead to an underestimation of the modeled critical supersaturation. For mixtures there may also the possibility of a slightly soluble salt forming. In the model solutions used for determining surface tension and water activity, no precipitate was observed for GF $>4$, indicating that the mixtures were fully soluble at activation conditions, but the model solutions might have been supersaturated. It must be stressed that the physical characteristics measured in bulk solutions may not mirror the physical processes and properties of an activating nano particle. The exact effect of sodium chloride and ammonium sulphate on the solubility of the investigated organic acids should be investigated further, in particular for the effect of sodium chloride on the solubility of oxalic acid dihydrate.

Even for fully soluble compounds it is also possible that mass transfer of the dissolving components is not fast enough to obtain a uniform solute distribution through the droplet volume, as suggested by Asa-Awuku and Nenes (2007). The consequence of such kinetic limitation is a lower solute concentration which can delay or even hinder activation. It has been concluded that mass transfer kinetics can contribute to reported discrepancies between theoretically predicted and experimentally observed CCN activity. The effect is especially relevant for compounds with low aqueous diffusivity, for example humic-like substances (Asa-Awuku and Nenes, 2007). It could therefore also be a relevant explanation of the discrepancies observed in this study. However, more information about the effect of salts on physical properties such as diffusivity and solubility is necessary.

Mass transfer limitation on the growth of activating droplets can also decrease the number concentration of droplets formed, even above the critical supersaturation (Nenes et al., 2001; Ruehl et al., 2008). It has been suggested that for example the formation of surface films can delay droplet growth (Asa-Awuku et al., 2009). Such effects could lead to fewer activated particles being detected in the $\mathrm{CCNC}$ and an overestimation of the supersaturation necessary to activate the studied particles. However, it was not possible to evaluate growth kinetics for these data sets.

Finally, the deviations between measured and modeled critical supersaturation may be related to surfactant partitioning, which can lead to an enhancement of water activity and surface tension. Droplets on the nano- or micrometer scale have much larger surface-to-volume ratios than macroscopic bulk solutions. Since surface active compounds are prefer- entially located at the surface, this means that a larger fraction of the surface active molecules can be present close to the surface of a droplet, relative to a macroscopic solution with the same concentration of surfactant. If a relatively large amount of surfactant molecules is residing in the surface of a droplet, the droplet bulk will be depleted, causing the surfactant to have a smaller effect on water activity (Sorjamaa et al., 2004; Prisle et al., 2008, 2010). At the same time, this will affect the Kelvin term (Li et al., 1998; Sorjamaa et al., 2004; Prisle et al., 2008) since the depression of the Kelvin term will be smaller than if partitioning was not accounted for. Neglecting surfactant partitioning may lead to a significant underestimation of the critical supersaturation ( $\mathrm{Li}$ et al., 1998; Sorjamaa et al., 2004; Prisle et al., 2008, 2010). This effect seems to be in play for the particles containing the more surface active compounds studied; in particular NRFA. Although we were not able to confirm it experimentally, surfactant partitioning is also expected to be important for particles containing cis-pinonic acid (Sorjamaa et al., 2004).

\section{Conclusions}

The CCN ability of particles composed of different organic acid-inorganic salt mixtures was investigated by measuring the surface tension and water activity of droplet solutions and comparing Köhler theory to measured critical supersaturations.

The surface tension depression was in most cases negligible in the concentration range relevant at activation and only the very early phase of droplet growth, where the solute concentration is high, would be influenced by the surface tension effect of these compounds. Since activation occurs in very dilute aqueous solutions droplets, there should be no effect on the critical supersaturation. This, however, does not apply to the mixtures containing NRFA or cis-pinonic acid. Solutions containing one of these organic surfactants and ammonium sulphate showed a significant surface tension depression at activation conditions, but compared to aqueous solutions of the pure cis-pinonic acid as reported by Varga et al. (2007), the effect of organic-inorganic mixtures on surface tension was smaller when seen as a function of growth factor. The presence of inorganic salts can therefore influence activation behavior by decreasing surface tension depression.

Water activities of the solutions were mainly influenced by the presence of inorganic salts due to the higher degree of dissociation. At a given growth factor, the water activity of an organic acid-inorganic salt mixture was higher than for the pure inorganic salt but lower than for the pure organic compound. Consequently, the chemical species and mass fraction of the inorganic salt can significantly influence activation: Particles with higher inorganic content were found to activate at lower critical supersaturation. The only exception was the mixtures containing oxalic acid dihydrate and ammonium sulphate. The activation behavior of such mixed 
particles depended only slightly on the mass ratio between the organic and inorganic compounds. A good correspondence was observed between measured water activity and the E-AIM model, and also between measured water activities and water activities calculated from estimated van't Hoff factors. However, in both cases deviations between measurements and models at activation of particles with small dry diameters were observed.

For mixed particles containing ammonium sulphate as the salt, Köhler theory based on parameterizations of surface tension and water activity compare well with experimentally obtained values of the critical supersaturation, except for particles containing the more surface active compounds, in particular NRFA. In these cases the critical supersaturation is significantly underpredicted and better described using the surface tension of water. This is ascribed to effects of surfactant partitioning.

Köhler theory based on parameterizations of surface tension and water activity underpredicts observed critical supersaturations for mixed particles of oxalic acid dihydrate and sodium chloride suggesting that the influence of sodium chloride on the solubility of the organic acid should be investigated further.

Acknowledgements. We acknowledge the FP6 projects Atmospheric Composition Change: an European network (ACCENT, contract No: GOCE-CT-2004-505337) and European Integrated project on Aerosol Cloud Climate and Air Quality interactions (EUCAARI, contract No: 036833-2) The authors would also like to thank the Hungarian Academy of Sciences for financial support and Hans-Christen Hansson at Stockholm University for lending the FTA 125 tensiometer for the measurements.

Edited by: V.-M. Kerminen

\section{References}

Albrecht, B. A.: Aerosols, Cloud Microphysics and Fractional Cloudiness, Science, 245, 1227-1230, 1989.

Allen, A. G., Baxter, P. J., and Ottley, C. J.: Gas and particle emissions from Soufrière Hills Volcano, Montserrat, West Indies: characterization and health hazard assessment, B Volcanol., 62, 8-19, doi:10.1007/s004450050287, 2000.

Asa-Awuku, A. and Nenes, A.: Effect of solute dissolution kinetics on cloud droplet formation: Extended Köhler theory, J. Geophys. Res., 112, D22201, doi:10.1029/2005JD006934, 2007.

Asa-Awuku, A., Engelhart, G. J., Lee, B. H., Pandis, S. N., and Nenes, A.: Relating CCN activity, volatility, and droplet growth kinetics of $\beta$-caryophyllene secondary organic aerosol, Atmos. Chem. Phys., 9, 795-812, doi:10.5194/acp-9-795-2009, 2009.

Bilde, M. and Pandis, S. N.: Evaporation rates and vapor pressures of individual aerosol species formed in the atmospheric oxidation of $\alpha$ - and $\beta$-pinene, Environ. Sci. Technol., 35, 3344-3349, doi:10.1021/es001946b, 2001.

Bilde, M. and Svenningsson, B.: CCN activation of slightly soluble organics: the importance of small amounts of inorganic salt and particle phase, Tellus B, 56, 128-134, doi:10.1111/j.16000889.2004.00090.x, 2004.

Bilde, M., Svenningsson, B., Mønster, J., and Rosenørn, T.: EvenOdd Alternation of Evaporation Rates and Vapor Pressures of C3-C9 Dicarboxylic Acid Aerosols, Environ. Sci. Technol., 37, 1371-1378, doi:10.1021/es0201810, 2003.

Booth, A. M. Topping, D. O., McFiggans, G. and Percival, C. J.: Surface tension of mixed inorganic and dicarboxylic acid aqueous solutions at $298.15 \mathrm{~K}$ and their importance for cloud activation predictions, Phys. Chem. Chem. Phys., 11, 8021-8028, 2009.

Broekhuizen, K., Kumar, P. P., and Abbatt, J. P. D.: Partially soluble organics as cloud condensation nuclei: Role of trace soluble and surface active species, Geophys. Res. Lett., 31, L01107, doi:10.1029/2003GL018203, 2004a.

Broekhuizen, K. E., Thornberry, T., Kumar, P. P., and Abbatt, J. P. D.: Formation of cloud condensation nuclei by oxidative processing: Unsaturated fatty acids, J. Geophys. Res.-Atmos., 109, D24206, doi:10.1029/2004JD005298, 2004b.

Capel, P. D., Gunde, R., Zurcher, F., and Giger, W.: Carbon speciation and surface tension of fog, Environ. Sci. Technol., 24, 722-727, doi:10.1021/es00075a606, 1990.

Cheng, Y., Li, S. M., Leithead, A., Brickell, P. C., and Leaitch, W. R.: Characterizations of cis-pinonic acid and n-fatty acids on fine aerosols in the Lower Fraser Valley during Pacific 2001 Air Quality Study, Atmos. Environ., 38, 5789-5800, doi:10.1016/j.atmosenv.2004.01.051, 2004.

Clegg, S. L., Seinfeld, J. H., and Brimblecombe, P.: Thermodynamic modelling of aqueous aerosols containing electrolytes and dissolved organic compounds, J. Aerosol Sci. 32, 713-738, doi:10.1016/S0021-8502(00)00105-1, 2001.

Corrigan, C. E. and Novakov, T.: Cloud condensation nucleus activity of organic compounds: a laboratory study, Atmos. Environ. 33, 2661-2668, doi:10.1016/S1352-2310(98)00310-0, 1999.

Cruz, C. N. and Pandis, S. N.: A study of the ability of pure secondary organic aerosol to act as cloud condensation nuclei, Atmos. Environ., 31, 2205-2-214, doi:10.1016/S13522310(97)00054-X, 1997.

Decesari, S., Facchini, M. C., Fuzzi, S., McFiggans, G. B., Coe, H., and Bower, K. N.: The water-soluble organic component of sizesegregated aerosol, cloud water and wet deposition from Jeju Island during ACE-Asia, Atmos. Environ., 39, 211-222, 2005.

Ervens, B., Feingold, G., Clegg, S. L., and Kreidenweis, S. M.: A modelling study of aqueous production of dicarboxylic acids: 2. Implication for cloud microphysics, J. Geophys. Res., 109, D15206, doi:10.1029/2004JD004575, 2004.

Ervens, B., Cubison, M. J., Andrews, E., Feingold, G., Ogren, J. A., Jimenez, J. L., Quinn, P. K., Bates, T. S., Wang, J., Zhang, Q., Coe, H., Flynn, M., and Allan, J. D.: CCN predictions using simplified assumptions of organic aerosol composition and mixing state: a synthesis from six different locations, Atmos. Chem. Phys., 10, 4795-4807, doi:10.5194/acp-10-4795-2010, 2010.

Facchini, M. C., Mircea, M., Fuzzi, S., and Charlson, R. J.: Cloud albedo enhancement by surface-active organic solutes in growing droplets, Nature, 401, 257-259, doi:10.1038/45758, 1999.

Facchini, M. C., Decesari, S., Mircea, M., Fuzzi, S., and Loglio, G.: Surface tension of atmospheric wet aerosol and cloud/fog droplets in relation to their organic carbon content and chemical composition, Atmos. Environ., 34, 4853-4857, 
doi:10.1016S1352-2310(00)00237-5, 2000.

Feingold, G.: Modeling of the first indirect effect: Analysis of measurement requirements, Geophys. Res. Lett. 30(19), 7-1-7-4, doi:10.1029/2003GL017967, 2003.

Frosch, M., Zardini, A. A., Platt, S. M., Müller, L., Reinnig, M.C., Hoffmann, T., and Bilde, M.: Thermodynamic properties and cloud droplet activation of a series of oxo-acids, Atmos. Chem. Phys., 10, 5873-5890, doi:10.5194/acp-10-5873-2010, 2010.

Giebl, H., Berner, A., Reischl, G., Puxbaum, H., Kasper-Giebl, A., and Hitzenberger, R.: CCN activation of oxalic and malonic acid test aerosols with the University of Vienna cloud condensation nuclei counter, J. Aerosol Sci., 33, 1623-1634, doi:10.1016/S00211-8502(02)00115-5, 2002.

Gorbunov, B., Hamilton, R., Clegg, N., and Toumi, R.: Water nucleation on aerosol particles containing both organic and soluble inorganic substances, Atmos. Res., 47-48, 271-283, doi:10.1016/S0169-8095(98)00035-0, 1998.

Hefter, G. T. and Tomkins, R. P. T. (eds.): The Experimental Determination of Solubilities, John Wiley and Sons, New York, 2003.

Henning, S., Rosenrn, T., D’ Anna, B., Gola, A. A., Svenningsson, B., and Bilde, M.: Cloud droplet activation and surface tension of mixtures of slightly soluble organics and inorganic salt, Atmos. Chem. Phys., 5, 575-582, doi:10.5194/acp-5-575-2005, 2005.

Hitzenberger, R., Berner, A., Kasper-Giebl, A., Löflund, M., and Puxbaum, H.: Surface tension of Rax cloud water and its relation to the concentration of organic material, J. Geophys. Res. Atmos, 107(D24), 4752, doi:10.1029/2002JD002506, 2002.

IPCC: Climate Change 2007: The Physical Science Basis. Contribution of Working Group I to the Fourth Assessment Report of the Intergovernmental Panel on Climate Change, Cambridge University Press, Cambridge, UK, 2007.

Kiss, G. and Hansson, H.-C.: Application of osmolality for the determination of water activity and the modelling of cloud formation, Atmos. Chem. Phys. Discuss., 4, 7667-7689, doi:10.5194/acpd-4-7667-2004, 2004.

Kiss, G., Tombácz, E., and Hansson, H.-C.: Surface Tension Effects of Humic-Like Substances in Aqueous Extract of Tropospheric Fine Aerosol, J. Atmos. Chem., 50, 279-294, doi:10.1007/s10874-005-5079-5, 2005.

Koehler, K. A., Kreidenweis, S. M., DeMott, P. J., Prenni, A. J., Carrico, C. M., Ervens, B., and Feingold, G.: Water activity and activation diameters from hygroscopicity data - Part II: Application to organic species, Atmos. Chem. Phys., 6, 795-809, doi:10.5194/acp-6-795-2006, 2006.

Kristensson, A., Rosenørn, T., and Bilde, M.: Cloud Droplet Activation of Amino Acid Aerosol Particles, J. Phys. Chem. A, 114, 379-386, doi:10.1021/jp9055329, 2010.

Lance, S., Nenes, A., and Rissman, T. A.: Chemical and dynamical effects on cloud droplet number: Implications for estimates of the aerosol indirect effect, J. Geophys. Res., 109, D22208, doi:10.1029/2004JD004596, 2004.

Li, Z., Williams, A. L., and Rood, M. J.: Influence of Soluble Surfactant Properties on the Activation of Aerosol Particles Containing Inorganic Solute, J. Atmos. Sci., 55, 1859-1866, 1998.

Low, R. D. H.: A theoretical study of nineteen condensation nuclei, Journal de Recherches Atmosphériques, 4, 65-78, 1969.

Nenes, A., Ghan, S., Abdul-Razzak, H., Chuang, P. Y., and Seinfeld, J. H.: Kinetic Limitations on Cloud Droplet Formation and Impact on Cloud Albedo, Tellus B, 53, 133-149, 2001.
Nenes, A., Charlson, R. J., Facchini, M.C., Kulmala, M., Laaksonen, A., and Seinfeld, J. H.: Can chemical effects on cloud droplet number rival the first indirect effect?, Geophys. Res. Lett., 29(17), 29-1-29-4, doi:10.1029/2002GL015295, 2002.

Padró, L. T., Asa-Awuku, A., Morrison, R., and Nenes, A.: Inferring thermodynamic properties from $\mathrm{CCN}$ activation experiments: single-component and binary aerosols, Atmos. Chem. Phys., 7, 5263-5274, doi:10.5194/acp-7-5263-2007, 2007.

Persson, L. M., Alsberg, T., Kiss, G., and Odham, G.: Online size-exclusion chromatography/electrospray ionisation mass spectrometry of aquatic humic and fulvic acids, Rapid Commun. Mass Sp., 14, 286-292, 2000.

Petters, M. D. and Kreidenweis, S. M.: A single parameter representation of hygroscopic growth and cloud condensation nucleus activity, Atmos. Chem. Phys., 7, 1961-1971, doi:10.5194/acp-71961-2007, 2007.

Petters, M. D., Kreidenweis, S. M., Prenni, A. J., Sullivan, R. C., Carrico, C. M., Koehler, K. A., and Ziemann, P. J.: The role of molecular size in cloud droplet activation, Geophys. Res. Lett., 36, L22801, doi:10.1029/2009GL040131, 2009.

Prenni, A. J., DeMott, P. J., Kreidenweis, S. M., Sherman, D. E., Russell, L. M., and Ming, Y.: The Effects of Low Molecular Weight Dicarboxylic Acids on Cloud Formation, J. Phys. Chem. A, 105, 11240-11248, doi:10.1021/jp012427d 2001.

Prisle, N. L., Raatikainen, T., Sorjamaa, R., Svenningsson, B., Laaksonen, A., and Bilde, M.: Surfactant partitioning in cloud droplet activation: a study of C8, C10, C12 and C14 normal fatty acid sodium salts, Tellus B, 60, 416-431, doi:10.1111/j.16000889.2008.00352.x, 2008.

Prisle, N. L., Raatikainen, T., Laaksonen, A., and Bilde, M.: Surfactants in cloud droplet activation: mixed organic-inorganic particles, Atmos. Chem. Phys., 10, 5663-5683, doi:10.5194/acp-105663-2010, 2010.

Raymond, T. M. and Pandis, S. N.: Formation of cloud droplets by multicomponent organic particles, J. Geophys. Res.-Atmos., 108(D15), 4469, doi:10.1029/2003jd003503, 2003.

Rissler, J., Svenningsson, B., Fors, E. O., Bilde M., and Swietlicki, E.: An evaluation and comparison of cloud condensation nucleus activity models: Predicting particle critical saturation from growth at subsaturation, J. Geophys. Res.-Atmos, 115, D22208, doi:10.1029/2010JD014391, 2010.

Ruehl, C. R., Chuang, P. Y., and Nenes, A.: How quickly do cloud droplets form on atmospheric particles?, Atmos. Chem. Phys., 8, 1043-1055, doi:10.5194/acp-8-1043-2008, 2008.

Saxena, P. and Hildemann, L. M.: Water-Soluble Organics in Atmospheric Particles: A Critical Review of the Literature and Application of Thermodynamics to Identify Candidate Compounds, J. Atmos. Chem., 24, 57-109, doi:10.1007/BF00053823, 1996.

Seidl, W. and Hänel, G.: Surface-active substances on rainwater and atmospheric particles, Pure Appl. Geophys., 121, 1077-1093, doi:10.1007/BF02590198, 1983.

Seinfeld, J. H. and Pandis, S. N.: Atmospheric Chemistry and Physics: from Air Pollution to Climate Change. Wiley Interscience Publication, John Wiley and Sons, New York, 1998.

Shulman, M. L., Jacobson, M. C., Carlson, R. J., Synovec, R. E., and Young, T. E.: Dissolution behavior and surface tension effects of organic compounds in nucleating cloud droplets, Geophys. Res. Lett., 23, 277-280, 1996.

Sorjamaa, R., Svenningsson, B., Raatikainen, T., Henning, S., 
Bilde, M., and Laaksonen, A.: The role of surfactants in Köhler theory reconsidered, Atmos. Chem. Phys., 4, 2107-2117, doi:10.5194/acp-4-2107-2004, 2004.

Streng, W. H.: Characterization of Compounds in Solution. Kluwer Academics/Plenum Publishers, New York, 2001.

Sullivan, R. C., Moore, M. J. K., Petters, M. D., Kreidenweis, S. M., Roberts, G. C., and Prather, K. A.: Effect of chemical mixing state on the hygroscopicity and cloud nucleation properties of calcium mineral dust particles, Atmos. Chem. Phys., 9, 33033316, doi:10.5194/acp-9-3303-2009, 2009.

Svenningsson, B. and Bilde, M.: Relaxed step functions for evaluation of CCN counter data on size-separated aerosol particles, J. Aerosol Sci., 39, 592-608, doi:10.1016/j.jaerosci.2008.03.004, 2008.

Svenningsson, B., Rissler, J., Swietlicki, E., Mircea, M., Bilde, M., Facchini, M. C., Decesari, S., Fuzzi, S., Zhou, J., Mønster, J., and Rosenørn, T.: Hygroscopic growth and critical supersaturations for mixed aerosol particles of inorganic and organic compounds of atmospheric relevance, Atmos. Chem. Phys., 6, 1937-1952, doi:10.5194/acp-6-1937-2006, 2006.
Tuckermann, R. and Cammenga, H. K.: The surface tension of aqueous solutions of some atmospheric watersoluble organic compounds, Atmos. Environ., 38, 6135-6138, doi:10.1016/j.atmosenv.2004.08.005, 2004.

Twomey, S. A., Piepgrass, M., and Wolfe, T. L.: An assessment of the impact of pollution on global cloud albedo, Tellus, 36A, 356-366, 1984.

Varga, Z., Kiss, G., and Hansson, H.-C.: Modelling the cloud condensation nucleus activity of organic acids on the basis of surface tension and osmolality measurements, Atmos. Chem. Phys., 7, 4601-4611, doi:10.5194/acp-7-4601-2007, 2007.

Wex, H., Hennig, T., Salma, I., Ocskay, R., Kiselev, A., Henning, S., Massling, A., Wiedensohler, A., and Stratmann, F.: Hygroscopic growth and measured and modeled critical super-saturations of an atmospheric HULIS sample, Geophys. Res. Lett., 34, L02818, doi:10.1029/2006GL028260, 2007.

Yaws, C. L.: Handbook of vapour Pressure, Gulf Publishing Company, Houston, London Paris, Zurich, Tokyo, 1994.

Young, K. C. and Warren, A. J.: A Reexamination of the Derivation of the Equilibrium Supersaturation Curve for Soluble Particles, J. Atmos. Sci., 49, 1138-1143, 1992. 